Gustaf Bruze

Male and Female Marriage Returns to Schooling

Department of Economics 


\title{
MALE AND FEMALE MARRIAGE RETURNS TO SCHOOLING
}

\author{
Gustaf Bruze \\ Department of Economics, Aarhus School of Business / \\ School of Economics and Management, Aarhus University
}

November 2010

\begin{abstract}
:
A collective marriage matching model is estimated and calibrated to quantify the share of returns to schooling that is realized through marriage. The predictions of the model are matched with US data on the relationship between schooling and wage rates, the division of time within the household, and the extent to which men and women sort positively on several traits in marriage. Counterfactual analysis conducted with the model, suggests that US middle aged men and women are earning in the order of 30 percent of their return to schooling through improved marital outcomes.
\end{abstract}

JEL Classification: D10, I21, J12

Keywords: Marriage, Sorting, Returns to Education

I thank the members of my thesis committee, Casey Mulligan, Ali Hortaçsu, and Jeremy Fox for their advice and support. I also thank Gary Becker, Sebastian Buhai, Steven Levitt, John List and Tiago Pinheiro for their comments. All remaining errors are my own. Contact the author at gustb@asb.dk. 


\section{Introduction}

Human capital theory has long recognized that men and women earn many returns to their investments in schooling, including the effect that schooling has on marital outcomes. Yet, almost all of the empirical literature on returns to schooling focuses on the relationship between schooling and individual labor market earnings. In this paper, I try to fill this gap by estimating the extent to which US men and women are currently earning their returns to schooling through improved marital outcomes.

To answer this question, I formulate a collective household model (Chiappori 1988) which is embedded within the matching framework of Crawford and Knoer (1981). The model is estimated with US data on the relationship between schooling and wage rates, the division of time within the household, and the extent to which men and women sort positively on several traits in marriage. I then use the model to quantify how schooling affects the material resources that men and women can acquire through marriage. The results indicate that middle aged US men and women are currently earning in the order of 30 percent of their return to schooling through marriage.

One important motivation for quantifying marriage returns to schooling is to understand the demand for schooling of both men and women. In many countries such as the US, women are devoting more and more time to schooling and now surpass men in terms of their educational attainment (see for example Goldin, Katz, and Kuziemko 1996). At the same time, the participation rate of women in the labor force is much lower than the corresponding rate for men. This suggests that other than labor market returns play a role when men and women make their schooling decisions (see Chiappori, Iyigun, and Weiss 2009 for an in-depth analysis).

A second motivation for estimating marriage returns to schooling is to understand the transmission of economic status across generations and how it is affected by parental choices. In particular, leading theories of intergenerational mobility such as that of Becker and Tomes (1986), emphasize how parents make investments in the human capital of their children which affect both their labor market and marriage market outcomes. Recent empirical evidence suggests that the marital effect is important as a significant fraction of the covariance between 
parent and child family income is generated through assortative mating (Ermisch, Francesconi, and Siedler 2006).

An early reference to marriage returns to schooling can be found in Becker (1960) who points out that "a woman receives indirect returns from college if it enables her to marry a man with a higher income than she would have married if she did not go to college”. Much of the following theoretical literature on marriage returns to schooling has focused on whether the presence of such returns leads to a hold-up problem, as many of the resources that men and women bring to marriage are public goods (Cole, Mailath, and Postlewaite 2001, Peters and Siow 2002, and Iyigun and Walsh 2007). A second line of theoretical research has investigated how the sexual division of labor in marriage may coordinate male and female human capital investments prior to marriage (Hadfield 1999, and Baker and Jacobsen 2007).

The empirical literature on marriage returns to schooling is very small. Most likely, this is due to the difficulties involved in constructing a welfare measure for married men and women. One possible approach is to assume that men and women split their total household earnings in half, and use their respective shares to finance the consumption of a private good. Such a measure has been used by Goldin (1992), and Lefgren and McIntyre (2006) who both estimate that US women have been earning about $50 \%$ of their total returns to schooling through marriage. A potential problem with a consumption measure based on household earnings is that it treats marriage as a zero sum game (every dollar gained by the wife is a dollar lost for the husband and vice versa). The easiest way to illustrate the problem is to consider how the consumption measure is applied to the household member with the highest earnings. If that household member remains single, he or she is assigned a consumption level equal to his or her entire earnings, whereas when married, he or she shares some of these earnings with a spouse without receiving anything in return. In that sense, marriage constitutes a loss to him or her.

To avoid such problems, I base the empirical work in this paper on the premise that marriage generates a surplus. In the household model that is estimated, men and women benefit from marriage due to consumption savings, the presence of public goods, and since household members can specialize towards market or housework. A consequence of this empirical strategy, is that marriage returns to schooling can be defined and estimated for both men and women in a 
perfectly symmetric way (the two empirical papers mentioned above only estimate marriage returns to schooling for women).

From a methodological point of view, this paper is part of a recent literature that tries to place the collective model of household behavior (Chiappori 1988) within the context of a general equilibrium marriage matching model. A similar approach is taken by Choo, Seitz, and Siow (2008), who integrate the marriage model of Choo and Siow (2006) with the collective model.

Choo, Seitz and Siow focus on developing a general marriage model that is tractable and can be estimated without computing stable marriage matchings. Such tractability is achieved by placing restrictions on the error terms of the matching model. A main result from their paper, is that the sharing of resources in marriage can be estimated not only with data on the labor supplies of husbands and wives, but also with data on who marries whom across a set of isolated marriage markets. In contrast, this paper uses a marriage matching model to address the quantitative issue of marriage market returns to schooling. The structure of the model economy is less restrictive as men and women do not have to be divided into discrete groups.

The rest of this paper is organized as follows. In section 2 below, I present the model that is estimated in this paper, and the key properties of the model equilibrium. In section 3 , I describe the data used for the analysis, and section 4 discusses the issue of identification. Section 5 presents the estimation method used, and section 6 the main results together with a number of robustness checks. Finally, section 7 concludes with a discussion of the main results of the paper.

\section{Model}

\section{A. Basic setup of model}

The economy is static and populated by $M$ men (indexed by $i=1,2, \ldots, M$ ), and $F$ women (indexed by $j=1,2, \ldots, F$ ). Men and women have the choice of remaining single, or marrying a member of the opposite sex. All agents are characterized by their years of schooling $s$, their nonlabor income $y$, their wage rate $w$, and a vector of additional characteristics that are specified below. 
Men and women derive utility from the consumption of a private consumption good $c$, leisure $l$, and a public household good $q$. Both men and women rank bundles of these commodities according to the Stone-Geary utility function

$$
u(c, l, q)=\phi \cdot \log \left(c-s_{c}\right)+\delta \cdot \log \left(l-s_{l}\right)+(1-\phi-\delta) \cdot \log \left(q-s_{q}\right)
$$

Furthermore, agents have a unit time endowment which can be used for leisure, housework $h$, and market work $1-h-l$. I normalize the price of the market good for single agents to one, which implies that the budget constraint for a single agent is

$$
c=y+w \cdot(1-h-l)
$$

In real life, a married couple can obtain more consumption services from a given amount of income, than if the two household members had lived apart as singles. I capture these effects in the model, by letting married agents face a price $p$ for the private consumption good that is lower than the price which single agents face. With subscripts $m$ and $f$ for husbands and wives respectively, the budget constraint for a married couple can then be written as

$$
p \cdot\left(c_{m}+c_{f}\right)=y_{m}+y_{f}+w_{m} \cdot\left(1-h_{m}-l_{m}\right)+w_{f} \cdot\left(1-h_{f}-l_{f}\right)
$$

I use a square root formula for household consumption savings, so that the price $p$ is equal to

$$
p=\frac{1}{\sqrt{2}} \approx 0.7
$$

\section{B. Wages}

The wages of men and women are modeled with standard Mincer equations. The log hourly wage of an agent depends on his or her years of schooling, experience, experience squared, IQ, and social background $\theta$. In the empirical implementation, I use AFQT scores as a proxy for IQ and treat the social background variable as a single factor that is estimated from measurements on the education and occupation of each respondent's two parents (see the data section below for more details). 
Given these assumptions, the log hourly wage for man $i$ is thus given by

$$
\log \left(w_{m}^{i}\right)=\beta_{m}^{1}+\beta_{m}^{2} \cdot s^{i}+\beta_{m}^{3} \cdot \exp ^{i}+\beta_{m}^{4} \cdot \exp 2^{i}+\beta_{m}^{5} \cdot I Q^{i}+\beta_{m}^{6} \cdot \theta^{i}+\varepsilon_{m}^{i}
$$

and the log hourly wage for woman $j$ is given by

$$
\log \left(w_{f}^{j}\right)=\beta_{f}^{1}+\beta_{f}^{2} \cdot s^{j}+\beta_{f}^{3} \cdot \exp ^{j}+\beta_{f}^{4} \cdot \exp 2^{j}+\beta_{f}^{5} \cdot I Q^{j}+\beta_{f}^{6} \cdot \theta^{j}+\varepsilon_{f}^{j}
$$

In these equations, the wage error terms $\varepsilon_{m}$ and $\varepsilon_{f}$ are independent across agents, independent of all the personal characteristics of an agent, and have normal distributions

$$
\varepsilon_{k} \sim N\left(0, \sigma_{\varepsilon, k}^{2}\right) \quad, \quad k=m, f
$$

\section{Household technology}

The public household good $q$ is produced with the housework inputs of the household members. I assume that the effective amount of human capital that each agent has available for housework grows exponentially with his or her years of schooling, IQ, and social background. For IQ and social background, I calibrate the model so that these two traits raise the productivity of men and women in housework at the same rate as they raise male and female labor market wages. For years of schooling, I use the same baseline calibration rule, but also consider specifications in which the effect of schooling on housework productivity is lower (see section 6 for more details).

More formally, I define the log of the effective amount of human capital of man $i$ as

$$
\log \left(B_{m}^{i}\right) \equiv \gamma \cdot s^{i}+\beta_{m}^{2} \cdot I Q^{i}+\beta_{m}^{3} \cdot \theta^{i}+e_{m}^{i}
$$

and the log of the effective amount of human capital of woman $j$ as

$$
\log \left(B_{f}^{j}\right) \equiv \gamma \cdot s^{j}+\beta_{f}^{2} \cdot I Q^{j}+\beta_{f}^{3} \cdot \theta^{j}+e_{f}^{j}
$$

Furthermore, an agent who is in a given percentile of the distribution of market wages conditional on his or her observable characteristics, is assumed to be in the same percentile of the distribution of housework productivity given his or her observable characteristics. More specifically, 


$$
\begin{array}{ll}
e_{m}^{i}=\pi \cdot \varepsilon_{m}^{i}, & \forall i \\
e_{f}^{j}=\pi \cdot \varepsilon_{f}^{j}, & \forall j
\end{array}
$$

for some parameter $\pi>0$.

To quantify the outcomes of the household production process, I use a linear production function for single agents

$$
q=B \cdot h
$$

and a CES production function for married agents

$$
q=\left(\left(B_{m} \cdot h_{m}\right)^{v}+\left(B_{f} \cdot h_{f}\right)^{v}\right)^{1 / v}, \quad v \leq 1
$$

I choose such a specification for three different reasons. First, the production functions for both single and married agents are constant returns to scale. Second, the CES functional form is flexible enough to capture any degree of substitutability between male and female housework. And third, the joint specification implies that a married couple in which only one of the household members devotes time to housework, produces the same quantity of the household good as that household member would have produced, had he or she lived alone as a single agent.

With a CES production function, the parameter $v$ which determines the elasticity of substitution between male and female housework, also determines the extent to which the two inputs are direct complements. Since the household production functions will be estimated from data on housework inputs, a potential concern is that the results of the analysis depend strongly on the particular functional forms chosen. To minimize these concerns, I therefore perform robustness checks in which I modify the household production function. Overall, these modifications have a very small effect on the estimated share of marriage returns to schooling, which suggests that other aspects of the model and data are driving the main results of the paper. 


\section{Single households}

Agents who are single obtain utility through the consumption of the market good, leisure, and the household good. Formally, single agents choose their market work, leisure and housework to maximize their utility subject to their budget constraint, household technology constraint, and time constraints. If $V_{o}$ is the utility obtained by a single agent, then this utility can be written as

$$
\begin{aligned}
& \text { (S) } \quad V_{o}(w, s, y)=\max u(c, l, q) \\
& \text { s.t) } \quad c=y+w \cdot(1-h-l) \\
& q=B \cdot h \\
& 0 \leq 1-h-l \leq 1, \quad l \leq 1, h \leq 1
\end{aligned}
$$

\section{E. Married couples}

Following the collective household literature ${ }^{1}$, I assume that allocations for married agents are efficient and use the labor supply and leisure of men and women as indicators of how couples share their resources. If $U_{m}$ and $U_{f}$ are the utilities that a husband and a wife obtain from the consumption of the market good, leisure, and the household good only, then by definition, these two utilities satisfy

(P) $\quad U_{m}=\max u\left(c_{m}, l_{m}, q\right)$

s.t) $\quad u\left(c_{f}, l_{f}, q\right) \geq U_{f}$

$$
\begin{aligned}
& p\left(c_{m}+c_{f}\right)=y_{m}+y_{f}+w_{m}\left(1-h_{m}-l_{m}\right)+w_{f}\left(1-h_{f}-l_{f}\right) \\
& q=\left(\left(B_{m} h_{m}\right)^{v}+\left(B_{f} h_{f}\right)^{v}\right)^{1 / v} \\
& 0 \leq 1-h_{k}-l_{k} \leq 1 \quad k=m, f \\
& l_{k} \leq 1, \quad h_{k} \leq 1 \quad k=m, f
\end{aligned}
$$

\footnotetext{
${ }^{1}$ See for example Chiappori (1988), and Chiappori, Fortin, and Lacroix (2002).
} 
In addition to the utility obtained from the consumption of commodities, married agents also obtain utility from the match with their spouse. I let $V_{m}$ and $V_{f}$ denote the total utility for men and women in marriage, and define this total utility as the sum of the utility obtained from the consumption of commodities, and the marriage match utility.

In detail, the total utility $\mathrm{V}_{m}^{i, j}$ that man $i$ obtains if he marries woman $j$ and receives utility $U_{m}^{i, j}$ from the consumption of commodities, is

$$
\mathrm{V}_{m}^{i, j}=U_{m}^{i, j}+\tau_{s} \cdot s_{m} \cdot s_{f}+\tau_{I Q} \cdot I Q_{m} \cdot I Q_{f}+\tau_{\theta} \cdot \theta_{m} \cdot \theta_{f}+\eta_{m}^{i}
$$

By analogy, the total utility $\mathrm{V}_{f}^{i, j}$ that woman $j$ obtains if she marries man $i$ and receives utility $U_{f}^{i, j}$ from the consumption of commodities, is

$$
\mathrm{V}_{f}^{i, j}=U_{f}^{i, j}+\tau_{s} \cdot s_{m} \cdot s_{f}+\tau_{I Q} \cdot I Q_{m} \cdot I Q_{f}+\tau_{\theta} \cdot \theta_{m} \cdot \theta_{f}+\eta_{f}^{j}
$$

In these equations, $\tau_{s}, \tau_{I Q}, \tau_{\theta}$ are parameters that contribute to the complementarities of the years of schooling, IQ, and social background of the husband and the wife in marriage, and which will be estimated from the patterns of sorting on these traits in equilibrium. With such a specification, it is possible to estimate how an additional year of schooling for a man or a woman affects the characteristics of his or her potential spouse, while controlling for the impacts of IQ and social background in the marriage market. In addition, $\eta_{m}$ and $\eta_{f}$ are random utility terms that captures the heterogeneity in preferences for marriage among men and women. These two random variables are independent across men and women, and normally distributed with parameters

$$
\eta_{k} \sim N\left(\mu_{k}, \sigma_{k}^{2}\right) \quad, \quad k=m, f
$$

\section{F. Marriage matching}

To model the formation of marriages between men and women, I use the matching framework of Crawford and Knoer (1981) which allows for an endogenous division of resources in marriage, 
also when utility is non-transferable. To maintain the structure of the chosen matching framework, I assume that there are a finite number of permitted allocations for each potential couple which differ in terms of how the resources available in marriage are divided between the husband and the wife.

More formally, let

$$
\Pi_{u}^{i, j}=\left\{\left(U_{m, a}^{i, j}, U_{f, a}^{i, j}\right)\right\}_{a=1, A}
$$

be the set of $A$ distinct pairs of utilities obtained from the consumption of commodities, which correspond to the permitted allocations for a potential couple $(i, j)$. Since allocations in marriage are assumed to be efficient, each husband utility $U_{m, a}^{i, j}$ is the value of the Pareto problem (P) specified above given that the wife obtains utility $U_{f, a}^{i, j}$.

I order these allocations so that the sequence of utilities for the husband is strictly decreasing

$$
U_{m, 1}^{i, j}>U_{m, 2}^{i, j}>\cdots>U_{m, A}^{i, j}
$$

and the sequence of utilities for the wife is strictly increasing. Figure 1 below illustrates three such pairs of utilities

$$
\left(U_{m}, U_{f}\right) \in\left\{\left(U_{m, a}, U_{f, a}\right)\right\}_{a=1,2,3}
$$

along the utility possibility frontier of a potential couple.

To each of these permitted utilities from the consumption of commodities, one can add the utility of the marriage match itself for the husband and the wife, to obtain the set

$$
\Pi_{v}^{i, j}=\left\{\left(V_{m, a}^{i, j}, V_{f, a}^{i, j}\right)\right\}_{a=1, A}
$$

of total permitted utilities in marriage. Ultimately, men and women care only about these total utilities when making decisions about if they should remain single or get married, and if so, with whom. However, the set of permitted allocations for a couple differ only in terms of the commodities that each of them receive, since the utility of the marriage match itself remains constant. 
A matching is defined as a specification of the men and women who are single, a one-to-one function $g$ from the set of married men to the set of married women, such that if man $i$ and woman $j$ are married, then

$$
j=g(i), \quad i=g^{-1}(j) \equiv f(j)
$$

and a division of utility

$$
\left(U_{m}^{i, j}, U_{f}^{i, j}\right) \in \Pi_{u}^{i, j}
$$

for every married couple $(i, j)$.

A matching is said to be individually rational, if there is no married agent that would prefer to be single. Moreover, a matching is said to be blocked by man $i$ and woman $j$, if there is a permitted division of resources $\left(U_{m}^{i, j}, U_{f}^{i, j}\right) \in \Pi^{i, j}$ between them, such that they both weakly prefer marriage under the permitted division to the matching, and at least one of them strictly prefers marriage under the permitted division. Finally, if an individually rational matching is not blocked by any pair of man and woman, then it is said to be stable.

In a framework such as the marriage model presented above, Crawford and Knoer (1981) prove that the set of stable matchings is non-empty. The proof proceeds by constructing an algorithm through which agents on one side of the market (men or women), propose to members of the opposite sex in stages by promising an allocation that delivers a given total utility to their potential future spouse. Every time an offer of marriage is rejected, the proposing party is forced to either raise his or her offer, propose to someone else, or remain single.

As in the college admissions model of Gale and Shapley (1962), the matching model that is employed in this paper has multiple stable matchings. I select the unique matching which is obtained when men propose to women.

\section{G. Properties of the equilibrium}

For agents who end up being single, the solution to their time allocation problem (S) leads to a demand system in leisure, housework, and market work: 


$$
\begin{aligned}
& l=\delta \cdot\left(1+\frac{y}{w}\right)+s_{l} \cdot(1-\delta)-\delta \cdot s_{c} \cdot \frac{1}{w}-\delta \cdot s_{q} \cdot\left(\frac{1}{B}\right) \\
& h=(1-\phi-\delta) \cdot\left(1-s_{l}+\frac{y}{w}\right)-(1-\phi-\delta) \cdot s_{c} \cdot \frac{1}{w}+(\phi+\delta) \cdot s_{q} \cdot\left(\frac{1}{B}\right) \\
& 1-l-h=\phi \cdot\left(1-s_{l}\right)-(1-\phi) \cdot \frac{y}{w}+s_{c} \cdot(1-\phi) \cdot \frac{1}{w}-\phi \cdot s_{q} \cdot\left(\frac{1}{B}\right)
\end{aligned}
$$

For married couples, analytical expressions for the solution to their time allocation problems are not available, as these allocations depend on the division of resources in marriage, which in turn is the endogenous outcome of the marriage matching process. To characterize the time allocations of married agents, I instead rely on the general properties of an efficient allocation. As is emphasized by the collective household literature, Pareto efficiency implies that the time allocation of a married couple can be thought of as if it was generated by a two-step process. First, the husband and the wife decide how much time they are each going to devote to housework, and thus, how much of the household good they will consume. Then, in a second stage, the couple divides the remaining resources between themselves and each household member chooses how to allocate his or her time between leisure and market work.

Due to the separability of the household good from consumption and leisure, the second stage problem of the husband and the wife is given by

$$
\begin{aligned}
& \max \quad \phi \cdot \log \left(c_{k}-s_{c}\right)+\delta \cdot \log \left(l_{k}-s_{l}\right) \quad k=m, f \\
& \text { s.t) } \quad p \cdot c_{k}+w_{k} \cdot l_{k}=\lambda_{k}
\end{aligned}
$$

where $\lambda_{m}$ and $\lambda_{f}$ are the resources devoted to the husband and the wife respectively. Given the budget constraint of the couple, these two shares have to satisfy

$$
\lambda_{m}+\lambda_{f}=y_{m}+y_{f}+w_{m} \cdot\left(1-h_{m}\right)+w_{f} \cdot\left(1-h_{f}\right)
$$

The equilibrium shares $\lambda_{m}$ and $\lambda_{f}$ are complicated objects that depend on the observable and unobservable characteristics of all agents in a given market, and the distributions of the random utility terms for these agents. I do not specify a given functional form for these sharing rules as 
part of the structural model. Rather, I treat the shares for men and women as unobserved random variables, and estimate the parameters of the model through simulation.

In the case of housework, the time inputs of husbands and wives can be characterized analytically when both of these household members supply time to market work. For such couples, efficiency in household production requires that the ratio of the marginal products of the housework of the husband and of the wife is proportional to the ratio of their wages:

$$
\frac{\partial q}{\partial h_{m}} / \frac{\partial q}{\partial h_{f}}=\frac{w_{m}}{w_{f}}
$$

This result is reminiscent of the solution to the cost minimization problem of a firm, which chooses its inputs so that the marginal rate of technical substitution equals the ratio of factor prices. In the case of a household at an interior solution, the costs of the time inputs to housework are the wage rates of the husband and the wife. With the CES production function, this relationship can be used to obtain an expression for the optimal ratio of male to female housework at an interior equilibrium, which is

$$
\frac{h_{m}}{h_{f}}=\left(\frac{w_{f}}{w_{m}}\right)^{\frac{1}{1-v}} \cdot\left(\frac{B_{m}}{B_{f}}\right)^{\frac{v}{1-v}}
$$

Since the household production function is constant returns to scale, the ratio of the marginal products of housework is invariant to the scale of production, so that the quantity of the household good $q$ drops out of the condition above. This makes it possible to identify the parameters of the household production function form data on inputs and factor costs alone (see Pollak and Wachter 1975).

Turning finally to levels of housework, closed form solutions are once again available for couples in which both the husband and the wife supply time to market work. Conditional on the amount of household goods produced, the derived demand for male and female housework is 


$$
\begin{aligned}
& h_{m}=q \cdot\left(B_{m}\right)^{\frac{v}{1-v}} \cdot\left(\frac{z}{w_{m}}\right)^{\frac{1}{1-v}} \\
& h_{f}=q \cdot\left(B_{f}\right)^{\frac{v}{1-v}} \cdot\left(\frac{z}{w_{f}}\right)^{\frac{1}{1-v}}
\end{aligned}
$$

where $z$ is the constant cost per unit of the household public good, which follows from the constant returns to scale assumption. The demand for the public good when both the husband and the work, is in turn

$$
q=(1-\phi-\delta) \cdot\left(\frac{1}{z}\right) \cdot\left(\left(w_{m}+w_{f}\right) \cdot\left(1-s_{l}\right)+y-2 \cdot s_{c} \cdot p\right)+s_{q} \cdot(\phi+\delta)
$$

\section{Data}

\section{A. NLSY}

To construct a set of marriage markets for men and women, I use cross-sectional data from the 2000 wave of the National Longitudinal Survey of Youth 1979. I limit myself to white men and women in the representative part of the survey, since marriages between whites and blacks in the US are very rare (see Wong 2003). For the group of white respondents, the median age difference between husbands and wives is 2 years. I therefore divide all male and female respondents in the NLSY into six different markets based on their birth year, so that men who were born in 1957 can marry women born in 1959, men born in 1958 can marry women born in 1960, and so on. This gives a total of six cohort based marriage markets which are displayed in Table 1.

For each of these six cohort marriage markets, I draw a total of 160 single or married men and women $^{2}$. To make sure that each of the six cohort samples is representative of the relevant population, I choose the number of single men, single women, and married couples in each market to match the sex ratio, and the ratio of singles to married agents in the $5 \%$ sample of the 2000 US Census. I also select the number of agents in each cohort sample, so that the

\footnotetext{
${ }^{2}$ Members of cohabiting households were not sampled.
} 
educational attainment of singles and married couples correspond to the distribution of these agents by educational attainment in the Census (more details about the sampling procedure can be found in Appendix A).

The NLSY does contain flow variables for the non-labor income that each household member received in the year of 2000. Instead of using this variable, I compute a new non-labor income variable as a $10 \%$ earnings flow on the entire stock of wealth of each household, minus an imputed value of last year's net savings. In the case of married couples, I then divide this nonlabor income stream so that husbands receive $60 \%$ of the non-labor income, and wives receive $40 \%{ }^{3}$. After these imputations, the overall ratio of non-labor income to wage earnings is $25 \%$ for the agents in the six constructed NLSY cohort marriage markets.

To construct a measure of each respondent's social background, I use information about the education and occupation of the respondent's parents. I first convert the variables on parental occupations into parental earnings by finding the mean annual earnings by gender for twelve specified occupational categories in the 1970 Census. I then estimate a single factor model and use it to reduce the four parental measurements on schooling and occupations (converted to earnings) into one "social background" index.

\section{B. ATUS}

The NLSY contains information about the time that men and women devote to market work, but no reliable information on the housework they perform. I therefore use the available variables on weeks and hours worked in the NLSY data to construct a measure of market work, and supplement the NLSY data with data from the 2003 American Time Use Survey (ATUS).

In the ATUS surveys, a single member of a large number of US households is asked to fill in a time diary for the previous day. The information obtained from these diaries is then used to construct stylized measures of time use for each respondent based on a number of pre-specified activities. To deal with variations across week days, I construct a housework measure by

\footnotetext{
${ }^{3}$ I also experimented with other divisions, but this had no effect on the overall results.
} 
weighting individual time diaries based on whether the diary was completed for a weekday, a Saturday, or a Sunday.

The providers of the ATUS data divide all of the respondent time use into 17 major categories. Loosely speaking, I classify the sum of the activities referred to as household activities, caring for household and non-household members, consumer purchases, obtaining professional services, performing household services, obtaining government services, and making telephone calls related to housework, as housework (see Appendix B for the exact definition of the housework variable). I then compute the mean levels of housework for a set of different household types and used this data in the estimation process. Since the model I employ has agents with a unit endowment of time, I assume that there are 16 hours per day available for market work, housework, and leisure, and then treat the residual of the unit time endowment and the sum of market work and housework as leisure.

\section{Identification}

The marriage matching model implies a set of reduced form equations for the time allocations of single agents. These equations together with data on time devoted to market work, leisure and housework, identify the preferences that men and women have over the market consumption good, leisure, and the public household good (this is not the only variation in the data that identifies the preferences of men and women over goods). The parameter $v$ of the household production function, which determines the elasticity of substitution for male and female housework, is in turn identified by the efficiency condition for male and female housework in couples where both spouses are working.

The parameters $\tau_{s}, \tau_{I Q}$, and $\tau_{\theta}$ which quantity the preferences that men and women have for marriage matches, are identified by the degree of sorting on these traits in marriage, as a larger parameter raises the extent to which these traits are direct complements. The random utility terms $\mu_{m}$ and $\mu_{f}$, are parameterized by their respective means and variances. The means are identified by the overall fraction of men and women who are married in equilibrium and by the observed market work of husbands and wives (which indicates how husbands and wives share their resources in marriage). The variance of the female marriage shock is normalized to 10 in 
the estimation procedure. With this normalization, the male variance term is then identified by how the fraction of men and women married varies by individual years of schooling and other observable characteristics.

\section{Estimation}

\section{A. Overview of method}

To estimate the marriage matching model, I rely on the method of simulated moments described in McFadden (1989), and Pakes and Pollard (1989). For a brief description of this estimation method, let $Y$ denote a vector of endogenous variables, let $X$ denote a vector of exogenous variables, let $\theta$ be a vector of $b$ parameters to be estimated that appear in the conditional density $f(y \mid x, \theta)$ of $Y$ given $X$, and let $\left(y_{n}, x_{n}\right)$ be a random sample of $n=1,2, \ldots, N$ observations from this density. Finally, let $g(y, x, \theta)$ be a vector of $d \geq b$ moment functions with expectations given $x$ equal to zero, if and only if the functions $g$ are evaluated at the true parameter vector $\theta=\theta_{0}$.

In the case of the marriage model that is estimated in this paper, the moment functions $g(y, x, \theta)$ cannot be expressed analytically since they involve expectations that are analytically intractable. The method of simulated moments therefore proceeds by replacing such expectations with approximations that are formed as averages across a large number of Monte Carlo simulations with the statistical model.

More formally, let $\hat{g}(y, x, \theta)$ be the vector of $d$ simulated moment functions, which have been formed by replacing intractable parts of the moment functions $g(y, x, \theta)$ with averages across $r_{N}$ Monte Carlo simulations. The simulated method of moments estimator $\widehat{\theta}_{S M M}$ is then defined as

$$
\hat{\theta}_{S M M}=\operatorname{argmin}\left[\left(\frac{1}{N} \cdot \sum_{i=1, N} \hat{g}\left(y_{i}, x_{i}, \theta\right)\right)^{\prime} \cdot \Omega \cdot\left(\frac{1}{N} \cdot \sum_{i=1, N} \hat{g}\left(y_{i}, x_{i}, \theta\right)\right)\right]
$$

for some positive definite ( $d x d$ ) weighting matrix $\Omega$. 
Under mild regularity conditions, the parameter estimates $\hat{\theta}_{S M M}$ obtained in this fashion are consistent as the square root of the number of observations $\sqrt{N}$ divided by the number of simulations $r_{N}$, converges to zero (McFadden 1989, and Pakes and Pollard 1989). To perform the estimation in an efficient way, I first produced a consistent estimate of the optimal weighting matrix, and then used this matrix in a second stage to obtain the final parameter estimates.

\section{B. Computation of equilibrium}

The structure of the estimated model does not rule out the possibility of corner allocations where one or both of the spouses in a married couple chooses not to work in the labor market. When I compute the stable matching of the marriage model, I therefore allow for corner allocations where married women choose not to devote any time to market work. Since middle age couples where only the wife is working are extremely rare though, I disregard efficient marriages which involve the husband not working in the labor market ${ }^{4}$.

For each potential couple, I allow for ten permitted allocations with a different division of resources between the husband and the wife. I also experimented with more permitted allocations per couple, but such a change had no impact on the result. I first compute the maximum utility that a wife can obtain in marriage while the husband receives at least his reservation utility. I then partition the interval of permitted offers from men to women so that these offers end up being spread with an equal dollar equivalent distance between them, over the interval from a woman's reservation utility to the maximum utility that she can receive in marriage.

To compute a stable matching in a market is time consuming because it involves solving a large number of numerical optimization problems for all conceivable couples (not only those that end up being married). I form simulated moments by generating $r_{N}=100$ Monte Carlo simulations with the marriage model. More information about the details of these computations can be found in Appendix C.

\footnotetext{
${ }^{4}$ At the estimated parameters, less than $2 \%$ of all potential marriages have efficient allocations in which the husband would not be supplying time to market work.
} 


\section{Pre-estimation of wage equations}

In a first stage, I estimate the parameters of the male and female wage equations by pooling all observations that are available in the panel structure of the NLSY data. I add a set of region dummies and year dummies to the specification of the Mincer equations that were presented in the model section above, and estimate these equations with wage data for white men and women in the representative part of the NLSY data who are 30 years or older. The parameter estimates for years of schooling, IQ, and social background are also used to calibrate the effect of these traits on the housework productivity of men and women.

For women, I first impute wages offers for married women who are not working by using the two-step method of Heckman (1974). I then run two separate OLS regressions on the set of all single and married men and women. The results from these two regressions are presented in Tables 2 and 3 below. As can be seen in these tables, men earn a return of about $6.4 \%$ on their investment in formal schooling in the labor market when controlling for social background and IQ scores, while the corresponding figure for women is $6.7 \%$.

Since the imputed log hourly wages in the NLSY data for men and women are likely to include big measurement error components, I follow Del Boca and Flinn (2006) and reduce the variance of log hourly wages by half in the estimation of the marriage model. The size of the reduction is motivated by the evidence from Bound, Duncan and Rodgers (1994), who compare self-reported and "true" hourly wages for factory workers and find that half of the variance of reported log hourly wages is due to measurement error.

\section{Moment conditions}

To estimate the remaining preference and production parameters of the model, I use moments based on time allocations and marital behavior. For market work and housework, I construct moments by separately comparing the observed and predicted allocations of time to these activities for single agents, married men, married working women, and married non-working women. I also include a moment for the fraction of men and women working. Finally, I include two orthogonality conditions for years of schooling and the difference between the observed and 
predicted levels of market work, and the observed and predicted labor market status of each agent.

To capture the marital behavior of men and women in the estimated model, I include a moment for the overall fraction of men and women married. I also include an orthogonality condition for years of schooling and the difference between the observed and expected marital status of each agent. Finally, I include a set of moments that are based on the degree of sorting on years of schooling, AFQT scores, and social background in marriage. To that end, I introduce three functions (one for each of the traits mentioned above) that are equal to the product of the deviation of the wife's trait from the mean, and the deviation of the husband's trait from the mean if the agent is married, and equal to zero otherwise. I then form three moment conditions equal to the difference between the observed and predicted values of these three functions. In total, this gives me 15 moments that are used to estimate the remaining 13 parameters.

\section{Results}

A. Overall estimation results

All of the estimated preference and production parameters in the baseline specification are displayed in Table 4. Under this specification, one year of schooling is assumed to raise the housework productivity of men and women by the same amount as it raises their labor market wages (by 6.55\% which is the average of the estimated labor market returns of $6.4 \%$ and $6.7 \%$ for men and women respectively and which appear in Tables 2 and 3).

As can be seen in Table 4, the household production parameter $v$ is estimated to be 0.61 , which implies that the elasticity of substitution for male and female housework is in the order of 2.6. The estimated value of $v$ also implies that a married couple produces $45 \%$ more of the household good than what the husband and the wife would do by themselves, if they supplied the same amount of time to housework as singles. This degree of complementarity for male and female housework is large, but does not appear to be unrealistic (see the robustness checks below for results with lower degrees of complementarity). 
Table 5 shows a summary of the observed levels of sorting in marriage. The observed correlations are based on data for white couples from the representative part of the 2000 NLSY data. As can be seen in the table, married couples sort positively on years of schooling, AFQT scores, social background, and hourly wages (see Appendix A for the imputation procedure that was used for AFQT scores and social background). The table also includes the predicted correlations for these traits from the estimated model which are very similar to the observed correlations.

In Table 6, I display the observed time allocations for four different types of agents, which exhibit the well known pattern of specialization as a function of comparative advantage. Relative to single agents, husbands specialize towards market work and spend less time in housework. Wives on the other hand, spend less time in market work relative to single agents, and devote more time to housework. In the bottom part of Table 6, I also display the predicted patterns of time allocations from the model. These predictions exhibit the same type of specialization that can be observed in the data.

In Figures 2 and 3, I show the observed and predicted fractions of women and men who are married as a function of their years of schooling. In the data, more schooling raises marriage rates for both men and women, and these overall patterns are replicated by the model. In Figure 4, I compare the fraction of married women who are working in the data and in the model by years of schooling. Overall in the data, $71 \%$ percent of married women are working while the corresponding fraction in the model is $75 \%$ percent. However, the rate at which the labor force participation of women grows by years of schooling is too low in the model. Figures 5 to 7 finally, display the fraction of time that working married women, married men, and singles devote to market work. The model predicts a level of market work for all these agents that is close to the levels observed in the data.

\section{B. Counterfactuals}

To quantify marriage returns to schooling, I use the estimated marriage matching model to evaluate what the counterfactual marital outcome would have been for a man or woman, if he or she had obtained an additional year of schooling. This counterfactual marital outcome involves 
the probability that he or she would be married, the characteristics of his or her spouse if married, and the fraction of resources that he or she would obtain in such a potential marriage.

To implement these counterfactuals, I introduce an additional man and woman in each cohort marriage market ${ }^{5}$. I then vary the years of schooling of the additional agents one at a time, and record their consumption outcomes across a large number of simulations. In these simulations, I keep the non-labor income, AFQT scores, and social background of the additional agents fixed. However, I adjust their wages and productivity in housework in accordance with their assigned years of schooling, and the parameters of the estimated Mincer equations.

To illustrate how the counterfactuals are performed, I consider the case of a man who increases his schooling from $s_{A}$ to $s_{B}$ years. I first simulate the model $S$ times at both these levels of schooling for the man, record his utility from the consumption of the market good, leisure, and the household good in each simulation, and form the mean utilities $u_{A}$ and $u_{B}$ for him across these two sets of simulations

$$
u_{A}=\frac{1}{S} \cdot \sum_{t=1, S} u_{A}^{t} \quad, \quad u_{B}=\frac{1}{S} \cdot \sum_{t=1, S} u_{B}^{t}
$$

I then perform a third set of simulations in which I assign the man $s_{B}$ years of schooling and increase his wage and housework productivity in accordance with the new level of schooling, but hold the quality of his marital outcome fixed. In the case where the man was single with $s_{A}$ years of schooling, I simply record the utility of the man as single with a higher wage and an increased level of productivity in housework. In the case where the man ended up being married with $s_{A}$ years of schooling, I construct a new intermediate marriage for him in which he has $s_{B}$ years of schooling, receives a higher wage and is more productive in housework, but remains married to the same wife as when he had $s_{A}$ years of schooling.

In this new intermediate marriage, I divide the available resources between the man and his wife so that the wife receives the same utility as in the original marriage when the man had $s_{A}$ years of schooling. Such a division of resources in the intermediate marriage is consistent with the predictions of a competitive model, in which resources are assigned to husbands and wives in

\footnotetext{
${ }^{5}$ I choose to introduce both a man and a woman so that the additional agents have a minimal impact on the sex ratio in each market.
} 
accordance with their marginal contributions to marital output (see for example Iyigun and Walsh 2007) ${ }^{6}$. Formally speaking, the model used in this paper does have a finite number of agents, but the number of agents is very large and the division of resources is endogenized to mimic the outcomes of a large marriage market in which men and women compete over spouses.

This procedure for married couples is illustrated in Figure 8, in which the original marriage of the man when he has $s_{A}$ years of schooling is represented with the point $A_{A}$ along the utility possibility frontier $U P F_{A}$. The figure also includes the counterfactual marriage for the man when he has $S_{B}$ years of schooling, which is represented by the point $A_{B}$ along the utility possibility frontier $U P F_{B}$. Finally, the figure contains the intermediate marriage which is illustrated by the point $A_{I}$ along the intermediate utility possibility frontier $U P F_{I}$. Notice how the wife in the intermediate marriage represented by the point $A_{I}$ receives the same utility as in the original marriage represented by the point $A_{A}$.

With this complete set of intermediate outcomes for the man, I can form his mean utility from the consumption of the market good, leisure, and the household good across all intermediate simulations as

$$
u_{I}=\frac{1}{S} \cdot \sum_{t=1, S} u_{I}^{t}
$$

If $\Lambda(u)$ is the inverse of the expenditure function that converts utilities into dollars, then the total difference in the dollar value of consumption for the man at the two levels of schooling can be expressed as $\Lambda\left(\mathrm{u}_{\mathrm{B}}\right)-\Lambda\left(\mathrm{u}_{\mathrm{A}}\right)$. Similarly, the consumption difference for the man that is due to improvements in his marital outcomes is $\Lambda\left(\mathrm{u}_{\mathrm{B}}\right)-\Lambda\left(\mathrm{u}_{\mathrm{I}}\right)$. I therefore compute the share of returns to schooling for the man that is realized through marriage as

$$
\text { share }=\frac{\Lambda\left(u_{B}\right)-\Lambda\left(\mathrm{u}_{\mathrm{I}}\right)}{\Lambda\left(\mathrm{u}_{\mathrm{B}}\right)-\Lambda\left(\mathrm{u}_{\mathrm{A}}\right)}
$$

\footnotetext{
${ }^{6}$ If the intermediate marriage allocation was modeled as the outcome of a bargaining process, the estimated share of marriage returns to schooling would be larger for both men and women.
} 
The counterfactual described above gives me an estimate of the importance of marital improvements for one man in one cohort market, as he increases his schooling from $s_{A}$ to $s_{B}$ years. I repeat this counterfactual for all the additional men and women in the model, and change their educational attainment in increments of one year of schooling, from 10 to 11, 11 to 12, and so on, up to 17 to 18 years of schooling. In Figure 9, I display the distribution of all these shares for men, and in Figure 10, I display the corresponding distribution for women. Finally, I take the median $^{7}$ of all these estimates and use it to summarize my results. In the case of men, the median is $29 \%$ and for women, the median is $28 \%$.

\section{Robustness Checks}

The overall results presented above were obtained under the assumption that one year of schooling raises the productivity of men and women in housework at the same rate as it raises their labor market wages. Some economists however, have estimated and argued that the return to schooling in housework is lower than the return in the labor market (see Grossman 2006 for a survey of the literature on non-market returns to schooling). I therefore conducted robustness checks in which I lowered the effect of schooling on housework productivity to 5\% and 3\% respectively. To obtain these new results, I recalibrated the model, estimated it again, and then performed new counterfactual experiments with the model at the new parameter values.

In table 7, I report the results of these robustness checks together with the baseline results. The second and third rows of the table indicate that lowering the effect of schooling on housework productivity does raise the estimated shares of marriage returns to schooling a little bit, but the shares never exceed $40 \%$. In that sense, variations in the effect of schooling on housework productivity has a fairly small effect on the overall results of the paper.

As mentioned above, the estimates of the elasticity of substitution in housework together with the choices of household production functions for married and single agents, implies that a married couple produces $45 \%$ more of the household good than what the husband and the wife would do by themselves, if they supplied the same amount of time to housework as singles. The

\footnotetext{
${ }^{7}$ Using means instead of medians gives shares of $28 \%$ for men and $28 \%$ for women.
} 
size of the surplus follows from an estimated parameter, but also depends on the particular functional forms that were used to quantify the household production process. To minimize the impact of these functional form assumptions, I therefore performed a second set of robustness checks in which I vary the surplus of married agents in household production relative to their single counterparts.

To that end, I consider a slightly generalized CES household production function for married agents

$$
q=A \cdot\left(\left(B_{m} \cdot h_{m}\right)^{v}+\left(B_{f} \cdot h_{f}\right)^{v}\right)^{1 / v}, \quad v \leq 1
$$

with an extra multiplicative productivity term $A$. Instead of setting $A$ equal to one as above in the baseline specification, I also consider specifications in which $A$ is equal to 0.85 and 0.70 . With such alternative specifications, it is no longer true that a married couple in which only one of the household members devotes time to housework, produces the same quantity of the household good as that household member would have produced, had he or she lived alone as a single agent. On the other hand, it is possible to consider how different assumptions about the direct complementarities of male and female housework in marriage affect the overall estimated share of marriage returns to schooling. In particular, the two values for $A$ imply that a married couple now produces $25 \%$ and $5 \%$ more of the household good than what the husband and the wife would do by themselves, if they supplied the same amount of time to housework as singles.

For this second set of robustness checks, I once again recalibrated the model, estimated it again, and then performed new counterfactual experiments with the model at the new parameter values. As the two bottom rows of Table 7 indicates, these changes once again have a very small impact on the overall results.

\section{Conclusion}

In this paper, I quantified the share of returns to schooling that middle aged US men and women are currently realizing through marriage. Such marriage returns were defined as the additional material resources that more educated men and women can acquire through marriage. For that 
purpose, I embedded a collective household model (Chiappori 1988) within the matching framework of Crawford and Knoer (1981). The model was then estimated from data on the relationship between schooling and wage rates, the division of time within the household, and the extent to which men and women sort positively on several traits in marriage.

To quantify marriage returns to schooling with the estimated marriage matching model, I addressed the counterfactual question of what the marital outcome would have been for men and women in the sample, if they had obtained an additional year of schooling. The overall results suggest that US middle aged men and women are currently realizing in the order of $30 \%$ of their returns to schooling through marriage.

Given these large marriage returns, human capital theory predicts that men and women should partly make their schooling choices on the basis of how their future marriage prospects are affected. Two recent empirical papers provide evidence consistent with such behavior. The first is the study by Charles and Luoh (2009), who examine how the incarceration of black males has affected black women in the US. Using variations in the incarceration rates across states, the authors find that black women in communities with fewer men respond to such changes in the sex ratio by increasing their investments in schooling.

A second similar study is that of Lafortune (2010) who analyzes the schooling choices of second generation US immigrants born around 1900. Because many of these second generation immigrants married within their own ethnic groups, the sex ratios they faced in marriage depended on the gender composition of new arriving immigrants to the US. As for black women, Lafortune finds that men who faced increasing competition in marriage from newly arriving immigrants responded to this change by increasing their investments in schooling. 


\section{Appendix A. Cohort Data from the NLSY}

To construct separate markets with men and women who can remain single, or marry a member of the opposite sex, I use 2000 data on white respondents from the representative part of the NLSY. The agents who appear in the marriage markets are all respondents in the original NLSY data set, but I also use data for their spouses to construct some moments used in the estimation process.

For the respondents, all the required data is available, except for data on their housework. The AFQT scores used in this paper are the cohort and gender adjusted percentiles of the raw total test scores. For social background, I estimate a single principal factor model with the data that is available on the years of schooling of the respondent's father and mother, and the earnings of these two parents (imputed from their occupations) which I denote by $\theta$ in the text above.

For the spouses of the respondents, there is no information on AFQT scores and social background. I therefore impute values for these two variables by forming cells based on the education, gender, occupation, and spouse education of all the respondents in the representative part of the NLSY survey. In the imputation, I use both the mean and the variance of these traits for each cell.

To make sure that each cohort sample is representative of the overall US population, I compute sex ratios, fractions of men and women married, and the educational distribution of the entire cohort of white men and women in the 5\% sample of the 2000 Census. Each separate cohort based marriage market is then constructed by drawing a number of single and married men and women to replicate these summary statistics.

Single agents and married men were included in the constructed sample if they worked last year. Married women were included regardless of their labor force status. All the included men and women in the constructed data set were either single agents who lived alone, or married agents (no cohabiting men and women were included). 
Appendix B. Activities from the ATUS Included in the Housework Measure

\begin{tabular}{ll}
\hline Time use category & Activities included in housework \\
\hline \hline 01 & None \\
03 & All activities \\
04 & All activities except 030103, 030104, 030105, and 030110 \\
05 & All activities except 040103, 040104, 040105, and 040110 \\
06 & None \\
07 & None \\
08 & All activities \\
09 & $080101,080102,080201-080203,080299,080301,080302$, \\
10 & All activities \\
11 & All activities \\
12 & None \\
13 & None \\
14 & None \\
15 & None \\
16 & None \\
17 & 160103,160108, and half of 169999 \\
& All traveling related to the housework activities above \\
\hline 0 &
\end{tabular}

Note. A list of the 17 pre-specified categories in the ATUS time use survey, and the activities that I include in the housework measure. The exact definitions of all of these activities can be found on the ATUS webpage http://www.bls.gov/tus/. 


\section{Appendix C. Computation of Equilibrium}

The equilibrium of the model was computed through the following steps:

1) The utility of being single was computed for all men and women.

2) The maximum utility that a woman could obtain in every marriage while the husband received his reservation utility as single was computed. Both allocations where the wife did and did not work were considered.

3) The maximum utility that a man could obtain in every marriage while the wife received her reservation utility as single was computed. Both allocations where the wife did and did not work were considered.

4) For marriages with a surplus, the interval between the highest obtainable utility for the wife and her reservation utility as single, was partitioned with 10 equispaced points in dollar equivalent terms.

5) For each of these ten utility values, the maximum utility that could be obtained by the husband was computed as the maximum over allocations where the wife did and did not work.

6) The matching algorithm from Crawford and Knoer (1981) was applied to the men and women in a given market and the values along the utility possibility frontier that were computed in the five steps above.

If the non-negativity constraint for male market work was binding in a couple, then a marriage between the husband and the wife was ruled out, that is, I discarded efficient allocations in which only the wife would have supplied time to market work. Such allocations appeared in less than $2 \%$ of all potential marriages in the model at the estimated parameters.

To experiment with the model, I also computed stable matchings when the utility possibility frontier of a couple was split into 20 and 30 allocations respectively. This had no impact on the results. To minimize the computational time, I therefore estimated the model with only 10 allocations along the utility possibility frontier of each couple. 


\section{References}

Baker, Matthew J., and Joyce P. Jacobsen. 2007. Marriage, Specialization, and the Gender Division of Labor, Journal of Labor Economics 25, no. 4: 763-793.

Becker, Gary S. 1960. Investing in Education and Research: Underinvestment in College Education?, American Economic Review 50, no. 2: 346-354.

Becker, Gary S., and Nigel Tomes. 1986. Human Capital and the Rise and Fall of Families, Journal of Labor Economics 4, no. 3: S1-S39.

Bound, John, Charles Brown, Greg Duncan, and Willard Rodgers. 1994. Evidence on the Validity of Cross-Sectional and Longitudinal Labor Market Data, Journal of Labor Economics 12(3): 345-68.

Charles, Kerwin K., and Ming C. Luoh. Forthcoming. Male Incarceration, the Marriage Market, and Female Outcomes, The Review of Economics and Statistics.

Chiappori, Pierre-André. 1988. Rational Household Labor Supply, Econometrica 56, no. 1: 6390.

Chiappori, Pierre-André., Bernard Fortin, and Guy Lacroix. 2002. Marriage Market, Divorce Legislation, and Household Labor Supply, Journal of Political Economy 110, no. 1: 37-72.

Chiappori, Pierre-André, Murat Iyigun, and Yoram Weiss. 2009. Investments in Schooling and the Marriage Market, American Economic Review 99, no. 5: 1689-1713.

Choo, Eugene, and Aloysius Siow. 2006. Who Marries Whom and Why? Journal of Political Economy 114, no. 1: 175-201.

Choo, Eugene, Shannon Seitz, and Aloysius Siow. 2008. The Collective Marriage Matching Model: Identification, Estimation, and Testing, Working Paper no. 704, Boston College, Department of Economics, Boston.

Cole, Harold L., George J. Mailath, and Andrew Postlewaite. 2001. Efficient Non-Contractible Investments in Large Economies, Journal of Economic Theory 101: 333-373.

Crawford, Vincent P., and Elsie M. Knoer. 1981. Job Matching with Heterogeneous Firms and Workers, Econometrica 49, no. 2: 437-450.

Del Boca, Daniela, and Christopher J. Flinn. 2006. Household Time Allocation and Modes of Behavior: A Theory of Sorts, IZA Discussion Papers 1821, Bonn.

Ermisch, John, Marco Francesconi, and Thomas Siedler. 2006, Intergenerational Mobility and Marital Sorting, Economic Journal 116 (July): 659-679.

Gale, David, and Loyd Shapley. 1962. College Admissions and the Stability of Marriage, American Mathematical Monthly 69: 9-15. 
Goldin, Claudia. 1992. The Meaning of College in the Lives of American Women: The Past Hundred Years, Working Paper no. 4099, National Bureau of Economic Research, Cambridge, MA.

Goldin, Claudia, Lawrence Katz, and Ilyana Kuziemko, 2006. The Homecoming of American College Women: A Reversal of the College Gender Gap, Journal of Economic Perspectives 20, no. 4: 133-56.

Grossman, Michael. 2006. Education and Nonmarket Outcomes, In Handbook of the Economics of Education, ed. Eric Hanushek and Finis Welch. Amsterdam, The Netherlands: North-Holland.

Hadfield, Gillian K. 1999. A Coordination Model of the Sexual Division of Labor, Journal of Economic Behavior and Organization 40, no. 2: 125-153.

Heckman, James. 1974. Shadow Prices, Market Wages, and Labor Supply, Econometrica 42, no. 4: 679-694.

Iyigun, Murat, and Randall P. Walsh. 2007. Building the Family Nest: Pre-Marital Investments, Marriage Markets, and Spousal Allocations, Review of Economic Studies 74, no. 2: 507-35.

Lafortune, Jeanne. 2010. Making Yourself Attractive: Pre-Marital Investments and the Returns to Education in the Marriage Market, Unpublished Manuscript, Department of Economics, University of Maryland, College Park.

Lefgren, Lars and Frank McIntyre. 2006. Examining the Relationship between Women's Education and Marriage Outcomes, Journal of Labor Economics 24, no. 4: 787-830.

McFadden, Daniel. 1989. A Method of Simulated Moments for Estimation of Discrete Response Models without Numerical Integration, Econometrica 57, no. 5: 995-1026.

Pakes, Ariel, and David Pollard. 1989. Simulation and the Asymptotics of Optimization Estimators, Econometrica 57, no. 5: 1027-1057.

Peters, Michael, and Aloysius Siow. 2002. Competing Premarital Investments, Journal of Political Economy 110, no. 3: 592-608.

Pollak, Robert A., and Michael L. Wachter. 1975. The Relevance of the Household Production Function and Its Implications for the Allocation of Time, Journal of Political Economy 83, no. 2: 255-277.

Wong, Linda. 2003. Why Do Only 5.5\% of Black Men Marry White Women? International Economic Review 44, no. 3: 803-826. 
Table 1: Cohort Based Marriage Markets in the NLSY Data

\begin{tabular}{ccccccc}
\hline Market & Male cohort & Female cohort & Male age & Female age & \# Men & \# Women \\
\hline \hline 1 & 1957 & 1959 & 43 & 41 & 79 & 81 \\
2 & 1958 & 1960 & 42 & 40 & 79 & 81 \\
3 & 1959 & 1961 & 41 & 39 & 79 & 81 \\
4 & 1960 & 1962 & 40 & 38 & 81 & 79 \\
5 & 1961 & 1963 & 39 & 37 & 81 & 79 \\
6 & 1962 & 1964 & 38 & 36 & 81 & 79 \\
\hline
\end{tabular}

Note. Number of men and women in the six constructed NLSY marriage markets. 
Table 2: Male Wage Equation

\begin{tabular}{|c|c|}
\hline Dependent Variable & Log male wages \\
\hline \multirow[t]{2}{*}{ Years of schooling } & 0.064 \\
\hline & $(0.003)$ \\
\hline \multirow[t]{2}{*}{ Social background } & 0.069 \\
\hline & $(0.008)$ \\
\hline \multirow[t]{2}{*}{ AFQT score } & 0.249 \\
\hline & $(0.026)$ \\
\hline \multirow[t]{2}{*}{ Experience } & 0.063 \\
\hline & $(0.007)$ \\
\hline \multirow[t]{2}{*}{ Experience squared } & -0.001 \\
\hline & $(2.5 \mathrm{E}-0.4)$ \\
\hline \multirow[t]{2}{*}{ North East Region } & 0.095 \\
\hline & $(0.017)$ \\
\hline \multirow[t]{2}{*}{ North Central Region } & -0.029 \\
\hline & $(0.015)$ \\
\hline \multirow[t]{2}{*}{ South Region } & -0.020 \\
\hline & $(0.016)$ \\
\hline \multirow[t]{2}{*}{ Constant } & 1.151 \\
\hline & $(0.069)$ \\
\hline \multicolumn{2}{|c|}{ Year dummies 1988-2002 } \\
\hline \# Observations & 12598 \\
\hline R-squared & 0.22 \\
\hline
\end{tabular}

Note. Regression of log male wages on male characteristics with pooled data over period of 1988 to 2002. Numbers in parentheses are standard errors. 
Table 3. Female Wage Equation

\begin{tabular}{|c|c|}
\hline Dependent variable & Log female wages \\
\hline \multirow[t]{2}{*}{ Years of schooling } & 0.067 \\
\hline & $(0.001)$ \\
\hline \multirow[t]{2}{*}{ Social background } & 0.022 \\
\hline & $(0.004)$ \\
\hline \multirow[t]{2}{*}{ AFQT score } & 0.286 \\
\hline & $(0.012)$ \\
\hline \multirow[t]{2}{*}{ Experience } & 0.073 \\
\hline & $(0.002)$ \\
\hline \multirow[t]{2}{*}{ Experience squared } & -0.001 \\
\hline & $(8.3 \mathrm{E}-05)$ \\
\hline \multirow[t]{2}{*}{ North East Region } & 0.076 \\
\hline & $(0.008)$ \\
\hline \multirow[t]{2}{*}{ North Central Region } & -0.111 \\
\hline & $(0.007)$ \\
\hline \multirow[t]{2}{*}{ South Region } & -0.013 \\
\hline & $(0.007)$ \\
\hline \multirow[t]{2}{*}{ Constant } & 0.758 \\
\hline & $(0.023)$ \\
\hline \multicolumn{2}{|c|}{ Year dummies 1988-2002 } \\
\hline \# Observations & 15069 \\
\hline R-squared & 0.66 \\
\hline
\end{tabular}

Note. Second stage regression of log female wages on female characteristics with pooled data over period of 1988 to 2002. Numbers in parentheses are standard errors. 
Table 4: Estimated Parameters

\begin{tabular}{clcc}
\hline Preferences over goods & & \\
\hline \hline$\varphi$ & weight for consumption & 0.495 & $(0.258)$ \\
$\delta$ & weight for leisure & 0.323 & $(0.310)$ \\
$\mathrm{S}_{\mathrm{c}}$ & subsistence consumption & -3.38 & $(3.45)$ \\
$\mathrm{S}_{\mathrm{l}}$ & subsistence leisure & -0.0108 & $(0.488)$ \\
$\mathrm{S}_{\mathrm{q}}$ & subsistence household good & -0.148 & $(0.230)$ \\
\hline Household technology & & \\
\hline $\mathrm{v}$ & exponent in CES technology & 0.612 & $(0.0699)$ \\
$\mathrm{I}_{\mathrm{N}}$ & standard error housework shock & 0.261 & $(0.318)$ \\
\hline Preferences over matches & & \\
\hline$\tau_{\mathrm{s}}$ & schooling & $5.74 \times 10^{-4}$ & $(0.0196)$ \\
$\tau_{\mathrm{IQ}}$ & IQ & 0.0151 & $(0.0355)$ \\
$\tau_{\theta}$ & social background & $1.75 \times 10^{-3}$ & $(0.0405)$ \\
$\mu_{\mathrm{m}}$ & mean marriage shock men & -0.367 & $(0.194)$ \\
$\mu_{\mathrm{f}}$ & mean marriage shock women & 5.33 & $(1.51)$ \\
$\sigma_{\mathrm{m}}$ & standard error marriage shock men & 0.247 & $(0.0696)$ \\
\hline
\end{tabular}

Note. Estimated parameters and standard errors. 
Table 5: Observed and Predicted Levels of Sorting

\begin{tabular}{lcc}
\hline & Observed Correlation & Predicted Correlation \\
\hline \hline Years of Schooling & 0,55 & 0,61 \\
Hourly Wages & 0,33 & 0,34 \\
AFQT scores & 0,35 & 0,44 \\
Social Background & 0,24 & 0,32 \\
Non-Labor Income & n.a. & 0,096 \\
\hline
\end{tabular}

Note. The observed levels of sorting were computed with observations on all the white respondents in the representative part of the NLSY79 survey. 
Table 6: Observed and Predicted Time Allocations

\begin{tabular}{lccc}
\hline & Market Work & Housework & Leisure \\
\hline \hline Observed Time Allocations & & & \\
\hline Singles & 0.43 & 0.21 & 0.46 \\
Husbands & 0.46 & 0.13 & 0.41 \\
Working wives & 0.29 & 0.35 & 0.36 \\
Non-working wives & 0 & 0.56 & 0.44 \\
\hline Predicted Time Allocations & & & \\
Singles & 0.38 & 0.22 & 0.40 \\
Husbands & 0.43 & 0.18 & 0.39 \\
Working wives & 0.32 & 0.32 & 0.36 \\
Non-working wives & 0 & 0.45 & 0.55 \\
\hline
\end{tabular}

Note. Figures refer to fraction of total time spent in the three activities of market work housework, and leisure. 
Table 7: Estimated Marriage Returns to Schooling

\begin{tabular}{lcc}
\hline & Men & Women \\
\hline \hline Baseline case & $29 \%$ & $28 \%$ \\
Gamma equals 5\% & $31 \%$ & $31 \%$ \\
Gamma equals 3\% & $29 \%$ & $39 \%$ \\
A equals 0.85 & & \\
& $29 \%$ & $28 \%$ \\
A equals 0.70 & & $29 \%$ \\
\hline
\end{tabular}

Note. Percentages refer to share of total returns to schooling that men and women realize through marriage. Baseline case is when return to schooling in housework equals the return to schooling in the labor market. Rows with alternative gammas refer to specifications in which the return to schooling in housework is lowered (to 5\% and 3\%). Finally, changes in the parameter A refer to variatons in the degree of complementarity between male and female housework. (See section 6 in text for all details). 


\section{Figure 1: Stylized Utility Possibility Frontier for a Married Couple}

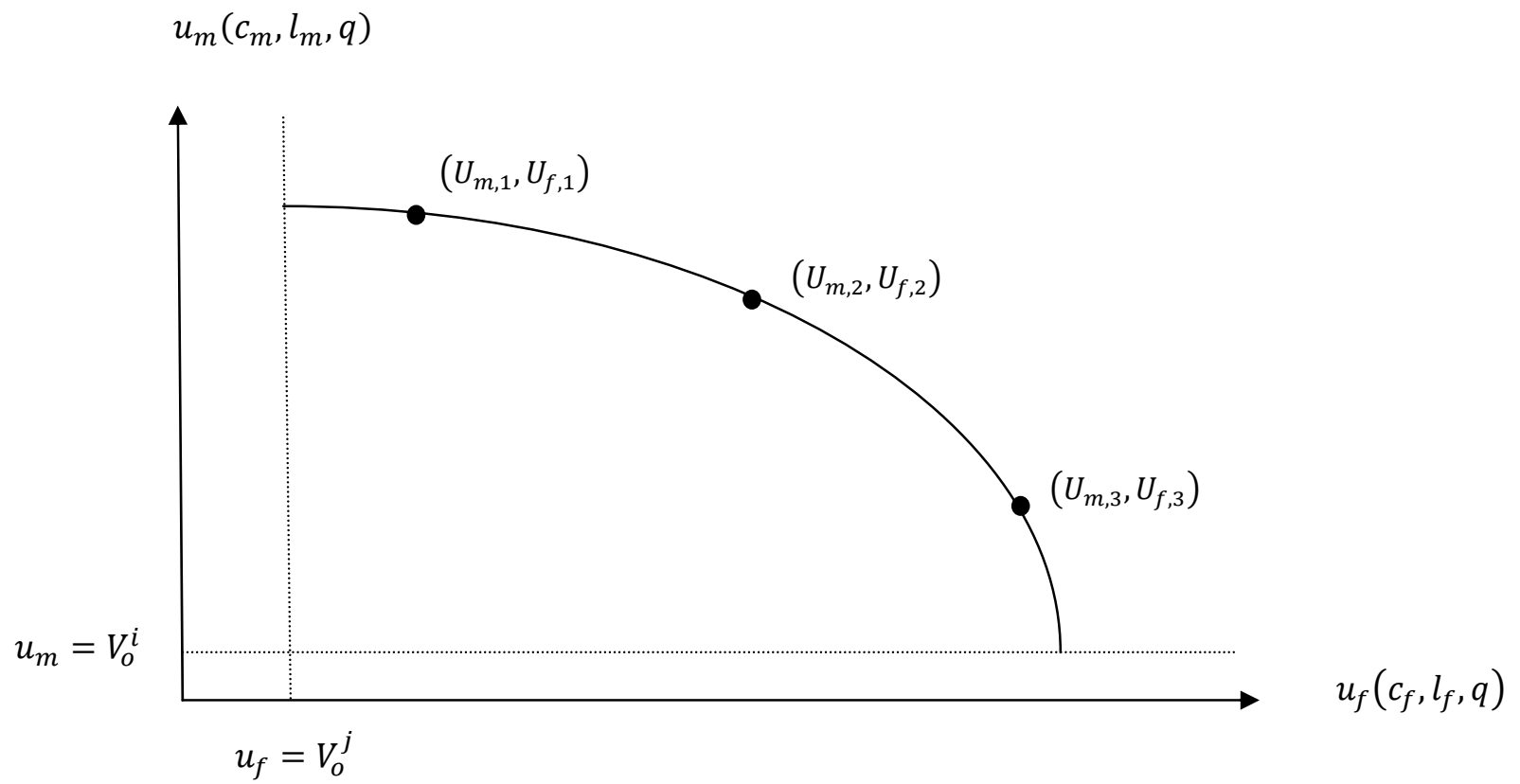

Note. Three permitted divisions of utility along a stylized utility possibility frontier of a married couple. The utility of the husband is plotted along the $y$-axis, and the utility of the wife is plotted along the x-axis. Only the part of the frontier above the reservation utilities of the husband and the wife (their utilities if they choose to remain single) is plotted since no marriages will takes place below these two levels. 


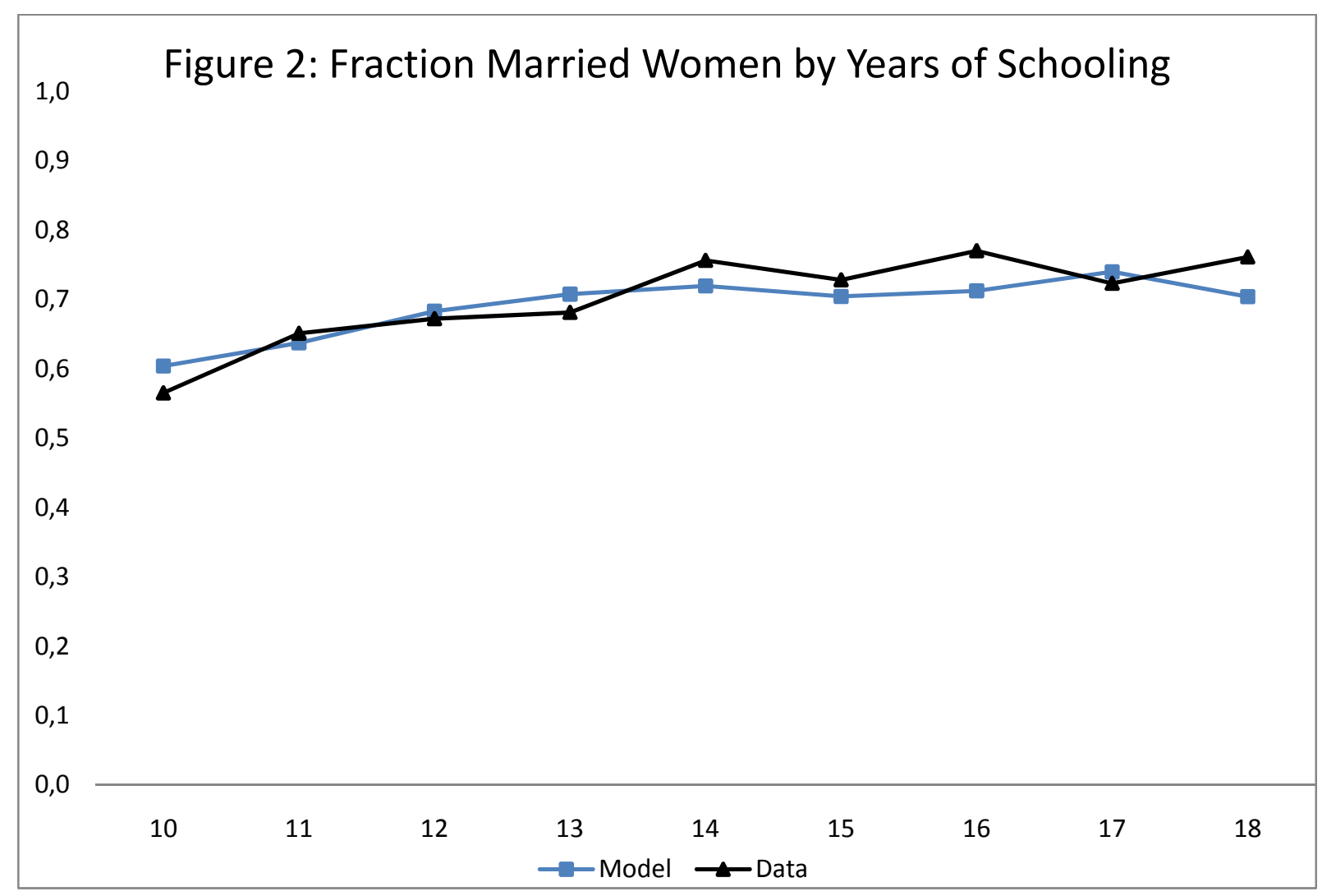

Note. Fraction married women by years of schooling in the model and in the data. The model outcome is the average over one hundred simulations with the model economy evaluated at the estimated parameters. The data sample consists of all the white women between the ages of 36 and 41 in the representative part of the2000 survey of the NLSY79 (a total of 1581 observations). 


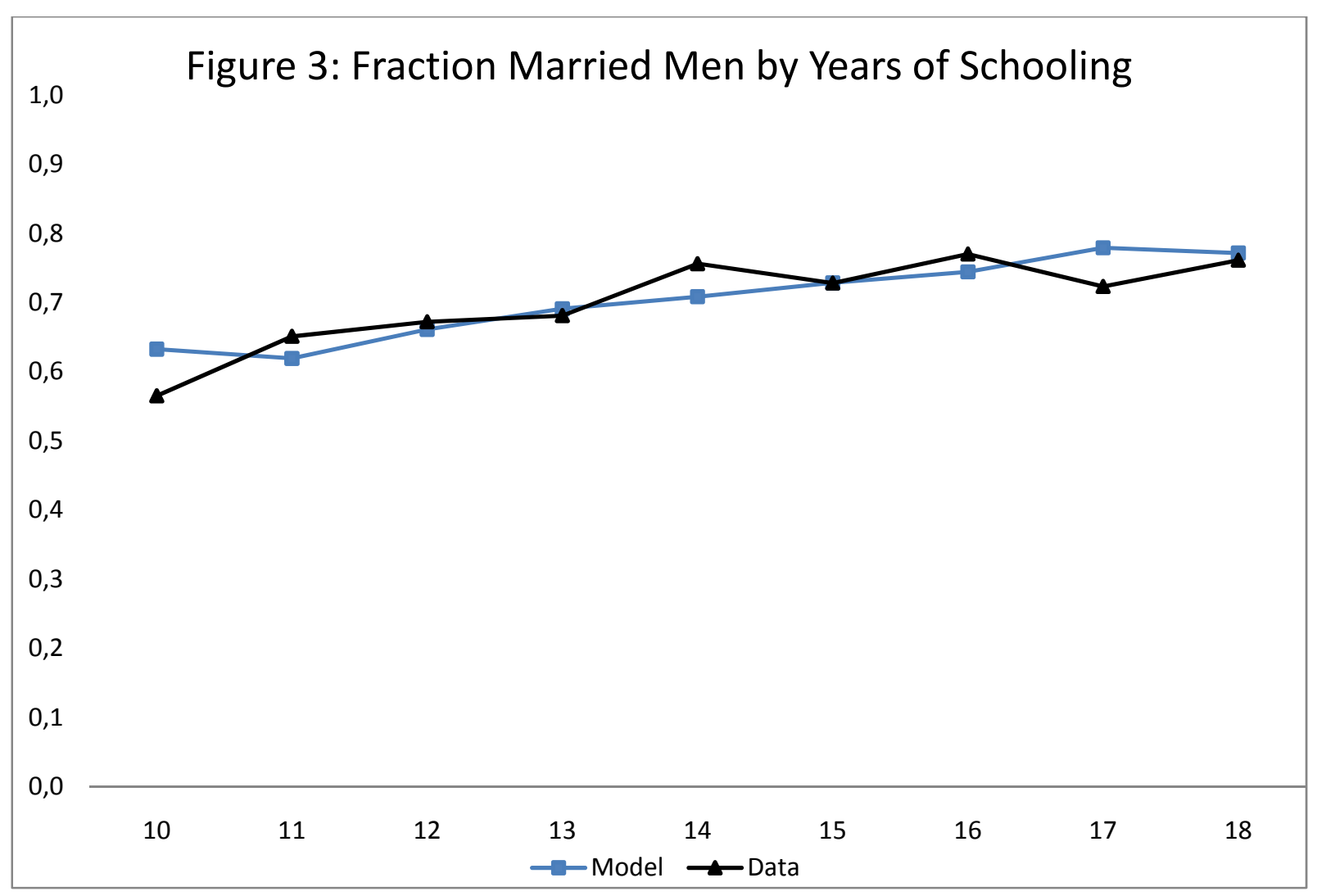

Note. Fraction married men by years of schooling in the model and in the data. The model outcome is the average over one hundred simulations with the model economy evaluated at the estimated parameters. The data sample consists of all the white men between the ages of 38 and 43 in the representative part of the2000 survey of the NLSY79 (a total of 1337 observations). 


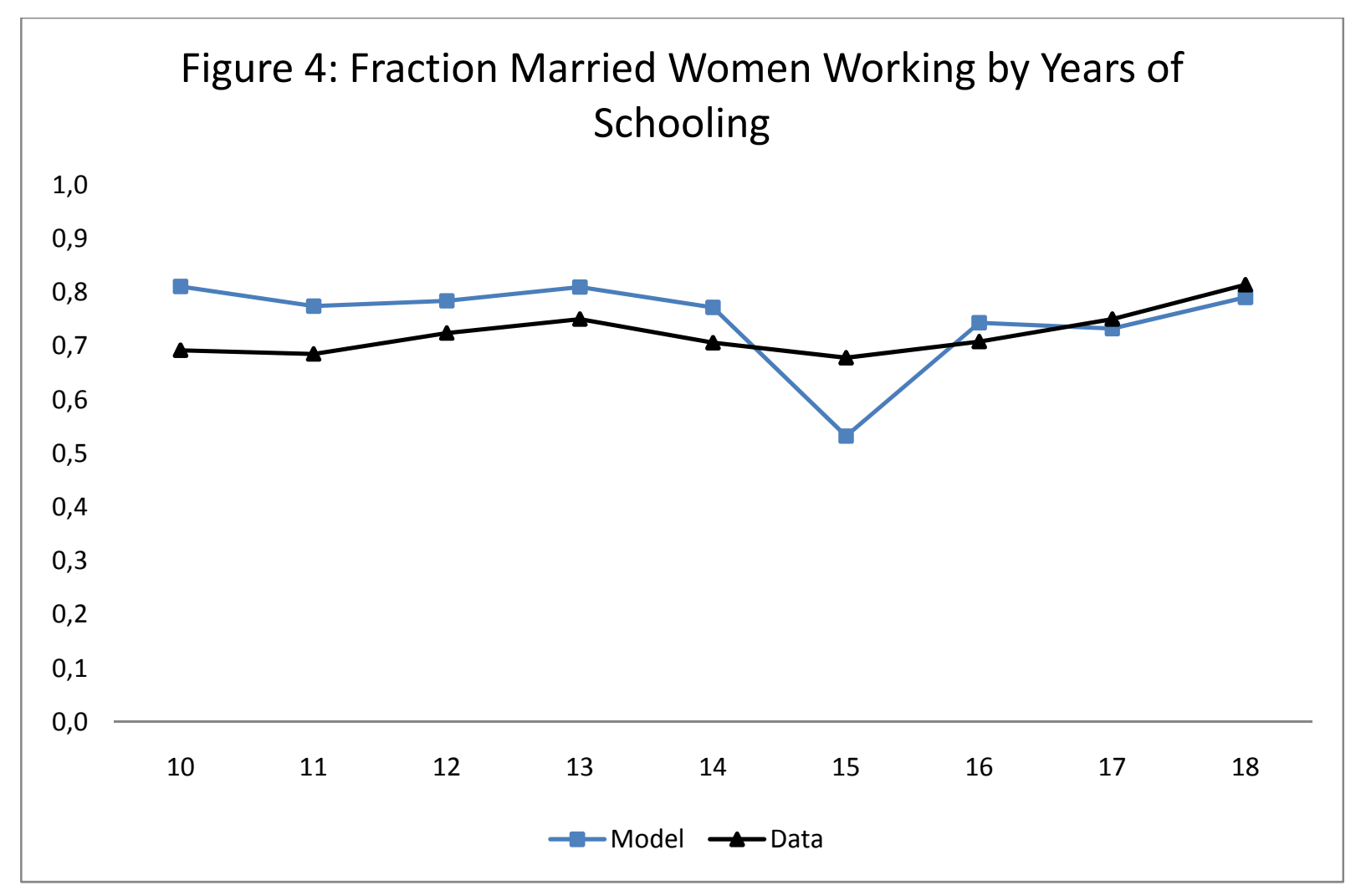

Note. Fraction married women working by years of schooling in the model and in the data. The model outcome is the average over one hundred simulations with the model economy evaluated at the estimated parameters. The data sample consists of all the married white women between the ages of 36 and 41 in the representative part of the2000 survey of the NLSY79 (a total of 1114 observations). 


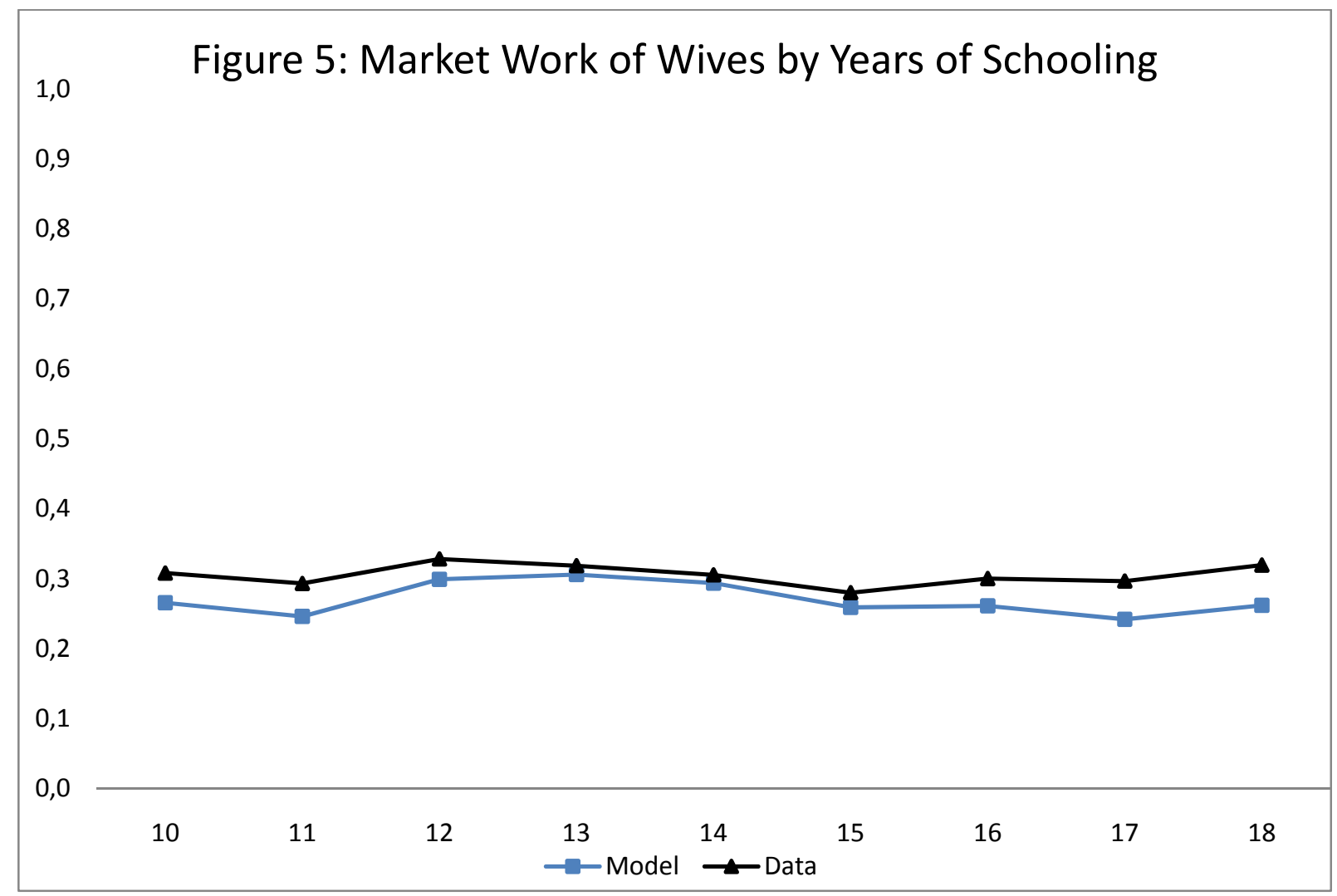

Note. Fraction of time married working women devote to market work in the model and in the data. The model outcome is the average over one hundred simulations with the model economy evaluated at the estimated parameters. The data sample consists of all the white working married women between the ages of 36 and 41 in the representative part of the2000 survey of the NLSY79 (a total of 895 observations). In the data, a day was assumed to consist of 14 hours available for market work, leisure, and housework. The fraction represented in the figure is the ratio of the total hours worked last year by the NLSY respondents, and their assumed total number of available hours. 


\section{Figure 6: Market Work of Husbands by Years of Schooling}

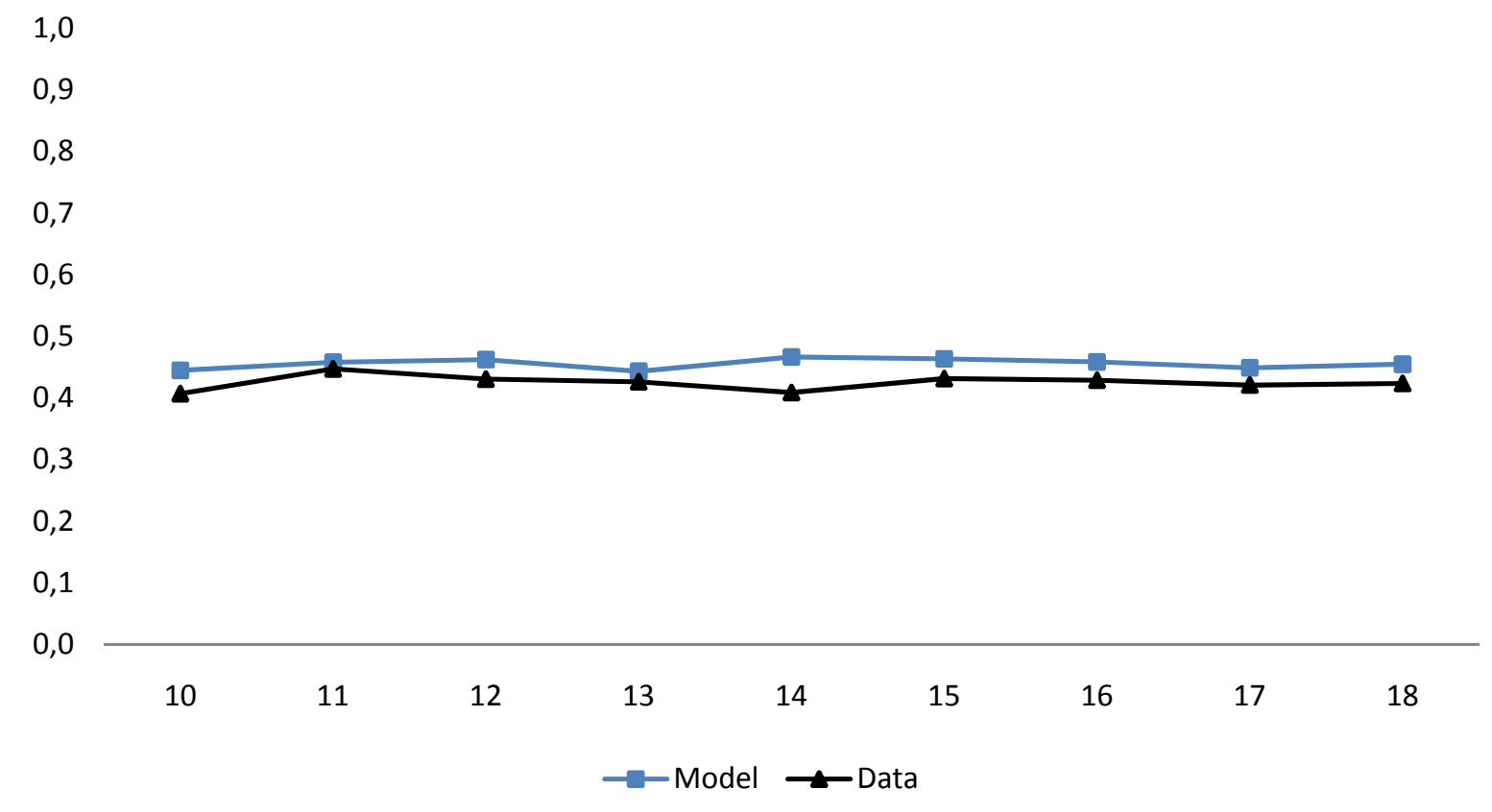

Note. Fraction of time married men devote to market work in the model and in the data. The model outcome is the average over one hundred simulations with the model economy evaluated at the estimated parameters. The data sample consists of all the white working married men between the ages of 38 and 43 in the representative part of the2000 survey of the NLSY79 (a total of 888 observations). In the data, a day was assumed to consist of 14 hours available for market work, leisure, and housework. The fraction represented in the figure is the ratio of the total hours worked last year by the NLSY respondents, and their assumed total number of available hours. 


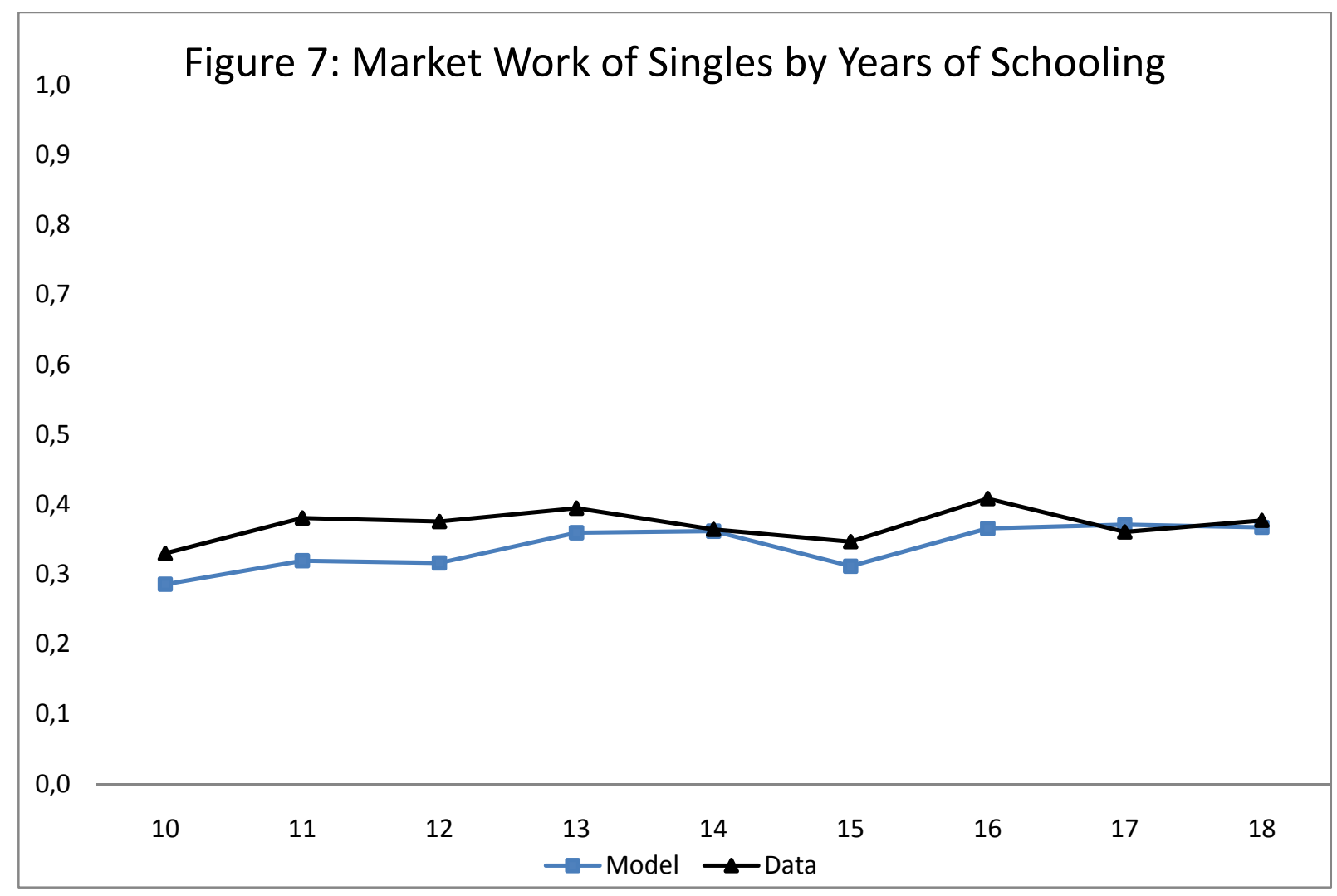

Note. Fraction of time single agents devote to market work in the model and in the data. The model outcome is the average over one hundred simulations with the model economy evaluated at the estimated parameters. The data sample consists of all the white working singles between the ages of 36 and 43 in the representative part of the2000 survey of the NLSY79 (a total of 790 observations). In the data, a day was assumed to consist of 14 hours available for market work, leisure, and housework. The fraction represented in the figure is the ratio of the total hours worked last year by the NLSY respondents, and their assumed total number of available hours. 


\section{Figure 8. Actual and Counterfactual Marital Outcomes}

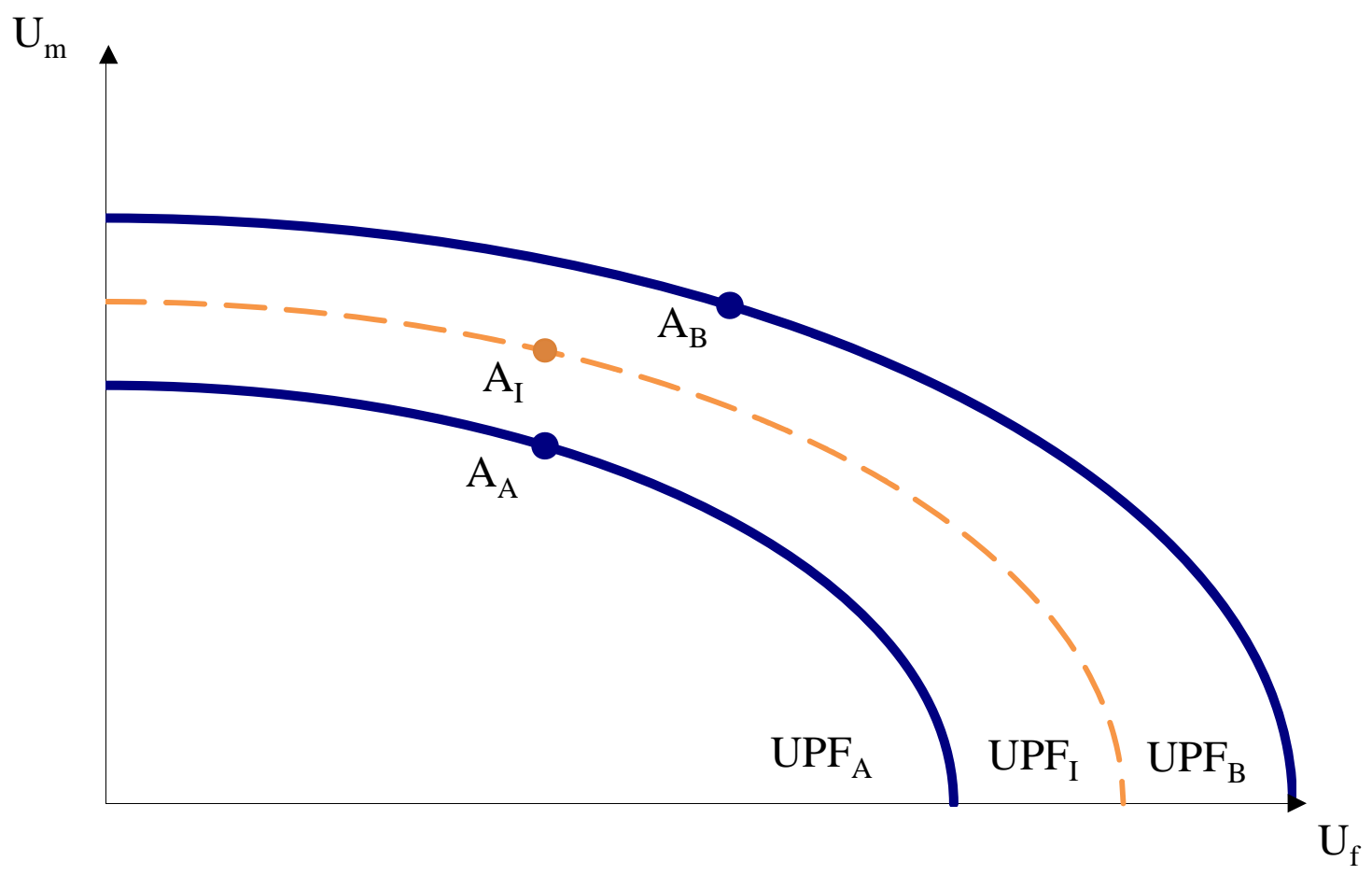

Note. The simulated allocations $A_{A}$ and $A_{B}$ correspond to allocations for a married man at two different levels of schooling. The intermediate marital outcome $A_{I}$ would be realized if the man obtained the higher years of schooling, but still married the same wife as in the allocation $A_{A}$. In the counterfactual simulations, the position of the intermediate allocation $A_{I}$ along the utility possibility frontier $U P F_{I}$ is chosen so that the utility of wife $\mathrm{A}$ is the same in allocations $A_{A}$ and $A_{I}$ (see the text in section 6 for more details). 


\section{Figure 9: Male Marriage Returns across Simulations}

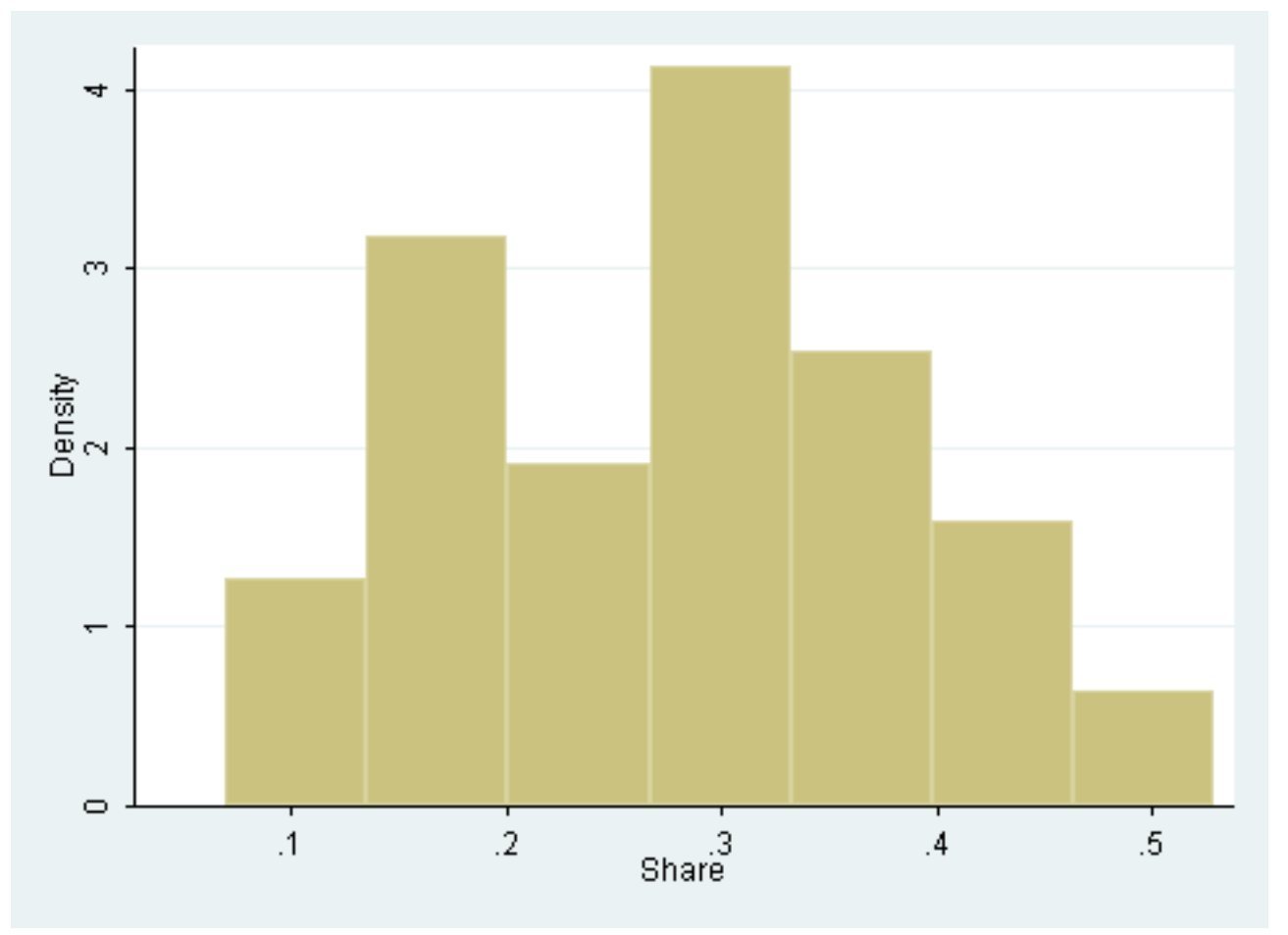

Note. Histogram for the share of male returns to schooling that are earned through marriage. Distribution is taken over all simulations across six different cohort based marriage markets, and 8 different one year increments of schooling (10 to 11,11 to 12 , and so on, up to 17 to 18 years of schooling). The median across all simulated shares is $29 \%$. 


\section{Figure 10: Female Marriage Returns across Simulations}

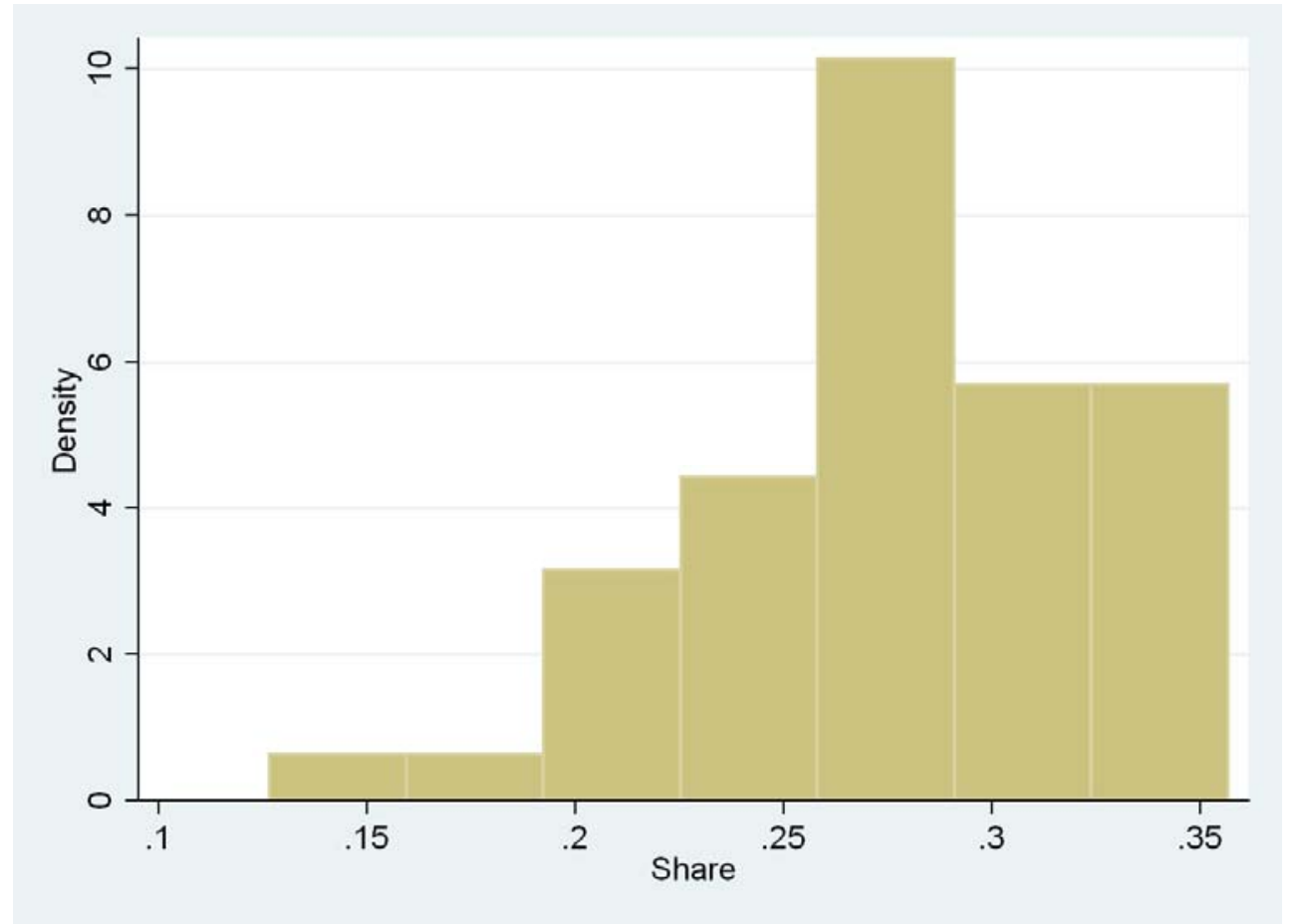

Note. Histogram for the share of female returns to schooling that are earned through marriage. Distribution is taken over all simulations across six different cohort based marriage markets, and 8 different one year increments of schooling (10 to 11,11 to 12 , and so on, up to 17 to 18 years of schooling). The median across all simulated shares is $28 \%$. 
Department of Economics:

Skriftserie/Working Paper:

2009:

WP 09-1 Tomi Kyyrä, Pierpaolo Parrotta and Michael Rosholm: The Effect of Receiving Supplementary UI Benefits on Unemployment Duration ISBN 9788778824035 (print); ISBN 9788778824042 (online)

WP 09-2 Dario Pozzoli and Marco Ranzani: Old European Couples' Retirement Decisions: the Role of Love and Money ISBN 9788778824165 (print); ISBN 9788778824172 (online)

WP 09-3 Michael Gibbs, Mikel Tapia and Frederic Warzynski: Globalization, Superstars, and the Importance of Reputation: Theory \& Evidence from the Wine Industry ISBN 9788778824189 (print); ISBN 9788778824196 (online)

WP 09-4 Jan De Loecker and Frederic Warzynski: Markups and FirmLevel Export Status ISBN 9788778824202 (print); ISBN 9788778824219 (online)

WP 09-5 Tor Eriksson, Mariola Pytliková and Frédéric Warzynski: Increased Sorting and Wage Inequality in the Czech Republic: New Evidence Using Linked Employer-Employee Dataset ISBN 9788778824226 (print); ISBN 9788778824233 (online)

WP 09-6 Longhwa Chen and Tor Eriksson: Vacancy Duration, Wage Offers, and Job Requirements - Pre-Match Data Evidence ISBN 9788778824240 (print); ISBN 9788778824257 (online)

WP 09-7 Tor Eriksson, Valérie Smeets and Frédéric Warzynski: Small Open Economy Firms in International Trade: Evidence from Danish Transactions-Level Data ISBN 9788778823861 (print); ISBN 9788778823878 (online)

WP 09-8 Dario Pozzoli and Marco Ranzani: Participation and Sector Selection in Nicaragua ISBN 9788778823885 (print); ISBN 9788778823892 (online) 
WP 09-9 Rikke Ibsen, Frederic Warzynski and Niels Westergård-Nielsen: Employment Growth and International Trade: A Small Open Economy Perspective ISBN 9788778823908 (print); ISBN 9788778823915 (online)

WP 09-10 Roger Bandick and Holger Görg: Foreign acquisition, plant survival, and employment growth ISBN 9788778823922 (print); ISBN 9788778823939 (online)

WP 09-11 Pierpaolo Parrotta and Dario Pozzoli: The Effect of Learning by Hiring on Productivity

ISBN 9788778823946 (print); ISBN 9788778823953 (online)

WP 09-12 Takao Kato and Pian Shu

Peer Effects, Social Networks, and Intergroup

Competition in the Workplace

ISBN 9788778823984 (print); ISBN 9788778823991 (online)

WP 09-13 Sanne Hiller and Erdal Yalcin: Switching between Domestic Market Activity, Export and FDI

ISBN 9788778824004 (print); ISBN 9788778824028 (online)

WP 09-14 Tor Eriksson and Mariola Pytlikova: Foreign Ownership Wage Premia in Emerging Economies: Evidence from Czech Republic ISBN 9788778824035 (print); ISBN 9788778824042 (online)

WP 09-15 Astrid Würtz Rasmussen: Family Structure Changes and Children's Health, Behavior, and Educational Outcomes ISBN 9788778824059 (print); ISBN 9788778824066 (online)

WP 09-16 Tor Eriksson: How Many Danish Jobs Can (Potentially) Be Done Elsewhere?

ISBN 9788778824073 (print); ISBN 9788778824080 (online)

WP 09-17 Lorenzo Cappellari, Claudio Lucifora and Dario Pozzoli: Determinants of Grades in Maths for Students in Economics ISBN 9788778824103 (print); ISBN 9788778824110 (online)

WP 09-18 Yingqiang Zhang and Tor Eriksson: Inequality of Opportunity and Income Inequality in Nine Chinese Provinces, 1989-2006 ISBN 9788778824127 (print); ISBN 9788778824134 (online) 
WP 09-19 Ricard Gil and Frederic Warzynski: Vertical Integration, Exclusivity and Game Sales Performance in the U.S. Video Game Industry ISBN 9788778824141 (print); ISBN 9788778824165 (online)

WP 09-20 Christian Gormsen: Intransparent Markets and Intra-Industry Trade ISBN 9788778824172 (print); ISBN 9788778824189 (online)

WP 09-21 Jan Bentzen and Valdemar Smith: Wine production in Denmark Do the characteristics of the vineyards affect the chances for awards?

ISBN 9788778824196 (print); ISBN 9788778824202 (online)

WP 09-22 Astrid Würtz Rasmussen: Allocation of Parental Time and the Long-Term Effect on Children's Education ISBN 9788778824233 (print); ISBN 9788778824240 (online)

2010:

WP 10-01 Marianne Simonsen, Lars Skipper and Niels Skipper:

Price Sensitivity of Demand for Prescription Drugs: Exploiting a Regression Kink Design ISBN 9788778824257 (print); ISBN 9788778824264 (online)

WP 10-02 Olivier Gergaud, Valérie Smeets and Frédéric Warzynski: Stars War in French Gastronomy: Prestige of Restaurants and Chefs'Careers ISBN 9788778824271 (print); ISBN 9788778824288 (online)

WP 10-03 Nabanita Datta Gupta, Mette Deding and Mette Lausten: Medium-term consequences of low birth weight on health and behavioral deficits - is there a catch-up effect? ISBN 9788778824301 (print); ISBN 9788778824318 (online)

WP 10-04 Jørgen Drud Hansen, Hassan Molana, Catia Montagna and Jørgen Ulff-Møller Nielsen: Work Hours, Social Value of Leisure and Globalisation ISBN 9788778824332 (print); ISBN 9788778824349 (online)

WP 10-05 Miriam Wüst: The effect of cigarette and alcohol consumption on birth outcomes ISBN 9788778824455 (print); ISBN 9788778824479 (online) 
WP 10-06 Elke J. Jahn and Michael Rosholm:Looking Beyond the Bridge: How Temporary Agency Employ-ment Affects Labor Market Outcomes ISBN 9788778824486 (print); ISBN 9788778824493 (online)

WP 10-07 Sanne Hiller and Robinson Kruse: Milestones of European Integration: Which matters most for Export Openness? ISBN 9788778824509 (print); ISBN 9788778824516 (online)

WP 10-08 Tor Eriksson and Marie Claire Villeval: Respect as an Incentive ISBN 9788778824523 (print); ISBN 9788778824530 (online)

WP 10-09 Jan Bentzen and Valdemar Smith: Alcohol consumption and liver cirrhosis mortality: New evidence from a panel data analysis for sixteen European countries ISBN 9788778824547 (print); ISBN 9788778824554 (online)

WP 10-10 Ramana Nanda: Entrepreneurship and the Discipline of External Finance ISBN 9788778824561 (print); ISBN 9788778824578 (online)

WP 10-11 Roger Bandick, Holger Görg and Patrik Karpaty: Foreign acquisitions, domestic multinationals, and R\&D ISBN 9788778824585 (print); ISBN 9788778824592 (online)

WP 10-12 Pierpaolo Parrotta, Dario Pozzoli and Mariola Pytlikova: Does Labor Diversity Affect Firm Productivity? ISBN 9788778824608 (print); ISBN 9788778824615 (online)

WP 10-13 Valérie Smeets and Frédéric Warzynski: Learning by Exporting, Importing or Both? Estimating productivity with multi-product firms, pricing heterogeneity and the role of international trade ISBN 9788778824622 (print); ISBN 9788778824646 (online)

WP 10-14 Tor Eriksson and Yingqiang Zhang: The Role of Family Background for Earnings in Rural China ISBN 9788778824653 (print); ISBN 9788778824660 (online)

WP 10-15 Pierpaolo Parrotta, Dario Pozzoli and Mariola Pytlikova: The Nexus between Labor Diversity and Firm's Innovation ISBN 9788778824875 (print); ISBN 9788778824882 (online) 
WP 10-16 Tor Eriksson and Nicolai Kristensen: Wages or Fringes?

Some Evidence on Trade-offs and Sorting

ISBN 9788778824899 (print); ISBN 9788778824905 (online)

WP 10-17 Gustaf Bruze: Male and Female Marriage Returns to Schooling ISBN 9788778824912 (print); ISBN 9788778824929 (online) 